\title{
Silver Nanoparticles Impair Retinoic Acid-Inducible Gene I Mediated Mitochondrial Anti- viral Immunity by Blocking the Autophagic Flux in Lung Epithelial Cells
}

Villeret $\mathbf{B}^{1,8}$, Dieu $A^{1,8}$, Straube $M^{1,8}$, Solhonne $B^{1}$, Miklave $P^{2}$, Hamadi $S^{3}$, Le Borgne $\mathbf{R}^{4}$, Mailleux $\mathbf{A}^{1}$, Norel $\mathbf{X}^{5}$, Aerts $\mathbf{J}^{6}$, Diallo $\mathbf{D}^{6}$, Rouzet $\mathbf{F}^{6}$, Dietl $\mathbf{P}^{7}$, Sallenave $\mathbf{J M}^{1}$, Garcia-Verdugo $\mathbf{I}^{*}$

1. INSERM, UMR U1152, Laboratoire d'Excellence Inflamex, Département HospitaloUniversitaire FIRE (Fibrosis, Inflammation and Remodeling), University Paris Diderot, Sorbonne Paris Cité, 75018 Paris, France.

2. Biomedical Research Centre, School of Environment and Life Sciences, University of Salford, Salford, UK.

3. Université Paris Est, ICMPE (UMR7182), CNRS, UPEC, F-94320 Thiais, France.

4. ImagoSeine, Electron Microscopy Facility, Institut Jacques Monod, CNRS UMR 7592, Université Paris Diderot, Sorbonne Paris Cité, 75205 Cedex 13 Paris, France.

5. INSERM, U1148, University Paris Nord, UMR-S1148, Paris, 75018, France.

6. AP-HP, Groupe Hospitalier Bichat-Claude Bernard, Service de Médecine Nucléaire, Paris, France Université Denis Diderot-Paris 7, U1148 Inserm, Paris, France.

7. Institute of General Physiology, University of Ulm, Albert-Einstein Allee 11, 89081 Ulm, Germany

8. These authors contributed equally

*To whom correspondence should be addressed: ignacio.garcia-verdugo@inserm.fr

Inserm UMR1152, Physiopathologie et Epidémiologie des Maladies Respiratoires Université Paris 7 Diderot, Faculté de Médecine, site Bichât, 16, rue Henri Huchard 75018 Paris, FRANCE. Tel: +33157277801. Fax : +33157277551. 


\begin{abstract}
Silver nanoparticles (AgNPs) are microbicidal agents which could be potentially used as alternative to antivirals to treat human infectious diseases, especially Influenza virus infection where antivirals have generally proven unsuccessful. However, concerns about the use of AgNPs on humans arise from their potential toxicity, although mechanisms are not well-understood. We show here, in the context of Influenza virus infection of lung epithelial cells, that AgNPs downregulated Influenza induced-CCL-5 and -IFN- $\beta$ release (two cytokines important in anti-viral immunity) through RIG-I inhibition, while enhancing IL-8 production, a cytokine important for mobilizing host antibacterial responses. AgNPs activity was independent of coating and was not observed with gold nanoparticles. Down-stream analysis indicated that AgNPs disorganized the mitochondrial network and prevented the anti-viral IRF-7 transcription factor influx into the nucleus. Importantly, we showed that the modulation of RIG-I-IRF-7 pathway was concomitant with inhibition of either classical or alternative autophagy (ATG-5- and Rab-9 dependent, respectively), depending on the epithelial cell type used. Altogether, this demonstration of a AgNPs-mediated functional dichotomy (down-regulation of IFN-dependent anti-viral responses and up-regulation of IL-8 -dependent antibacterial responses) may have practical implications for their use in the clinic.
\end{abstract}

Keywords: nano-toxicology, silver nanoparticles, influenza, mitochondria, CCL-5, interferon, autophagy 
Silver nanoparticles (AgNPs) have long been studied for their antibacterial properties ${ }^{1}$, and more recently, antiviral effects have also been described. ${ }^{1,2}$ However, in general, mechanisms explaining antimicrobial activity of AgNPs are not well-understood. It has been proposed that silver ions $(\mathrm{Ag}+)$ released from AgNPs might compromise the envelope integrity and/or the metabolism of the target pathogen, ${ }^{3}$ but free $\mathrm{Ag}+$ release in the cytoplasm of AgNPs-loaded eukaryotic cells has also been associated to cellular toxicity ${ }^{4,5}$ and damage to the host. ${ }^{6,7}$

These adverse effects could be explained by NPs-mediated modulation of the activity of immune and stromal cells such as macrophages and epithelial cells. Indeed, AgNPs have been shown to modulate pro-inflammatory cytokines (TNF $\alpha$, IL-1 $\beta$, IL-8, IL-6) levels in these cells. ${ }^{8-10}$ The mechanisms involved are diverse and may involve alterations in reactive oxygen species (ROS) production and in perturbations of the mitochondrial respiratory chain. ${ }^{8,11,12}$ Recently it has also been proposed that toxicity of AgNPs could also be related to a blockade of the autophagic flux. ${ }^{13}$ Autophagy is a natural process consisting in the degradation of cytoplasmic constituents. ${ }^{14}$ During conventional autophagy, cytoplasmic constituents first accumulate in autophagosomes (a process driven by autophagy related-proteins (ATGs), notably ATG-5 which promotes the conversion of soluble LC3-I to LC3-II in an autophagosome-membrane protein, also characterized by the presence of sequestosome 1 (SQSTM1)/p62 protein). The autophagosomes then fuse with lysosomes, resulting in the degradation of cytoplasmic materials, including p62. ${ }^{15}$ In addition to that succession of events, an alternative pathway of autophagy has also been recently described. ${ }^{16}$ The latter is independent of ATG5 and conversion of LC3-I to LC3-II does not occur. Unlike conventional autophagy, the formation of autophagosomes requires Rab9, ${ }^{15}, 16$ a GTPase essential for the trafficking of proteins from late endosomes to trans-Golgi membranes. 
In addition to serving a 'house keeping function', ATG proteins have been shown to also act as negative regulators of antiviral immunity by blocking interferon (IFN) signalling pathway at the mitochondria level. ${ }^{17}$ IFN signalling pathway is activated upon recognition of viral RNA by the cytosolic Retinoic Acid-Inducible Gene I (RIG-I) protein. ${ }^{18}$ After ligand binding, RIG-I associates to Mitochondrial Antiviral Signalling (MAVS) protein ${ }^{19}$ located on the outer mitochondrial membrane and the complex activates the expression of inflammatory and antiviral genes.

In that context, we set up to study here whether AgNPs may modulate the autophagic flux in the context of Influenza virus infection and whether they impact negatively on antiviral responses engaged by epithelial cells, the main target of Influenza virus.

We show here that following Influenza infection of lung epithelial cells, AgNPs inhibit the IFN signalling pathway through the inhibition of RIG-I-IRF-7-dependent release of CCL-5 and IFN$\beta$, two important anti-viral cytokines. This correlated with the disorganization of the mitochondrial network and enhanced partition of IRF-7 in the cytosolic and mitochondrial fractions at the expense of the nuclear fraction, leading to a blockade of the autophagic flux.

Importantly, we observed a 'dichotomy' in the action of AgNPs: the latter down-regulated IFNdependent anti-viral responses, as explained above, but conversely up-regulated IL-8, an important cytokine for host antibacterial responses due to its chemoattractant activity towards neutrophils. ${ }^{20}$ 


\section{RESULTS AND DISCUSSION}

\section{AgNPs down-regulate Influenza-induced CCL-5 and IFN- $\beta$ secretion in human lung epithelial cells independently of nanoparticle coating.}

Because internalisation is a critical step for nanoparticle activity, we first studied if wellcharacterized AgNPs (Table-1, Fig-S1) were internalized by several lung epithelial cells lines. Dark-field microscopy images of AgNPs-treated cells showed that AgNPs were associated to lung epithelial cells after $18 \mathrm{~h}$ of incubation (Fig-1). Further, video-microscopy of live cells showed that AgNPs associated with cytoplasmic vesicles in the bronchial epithelial cell line NCIH292 (Video-S1) and in primary rat type II cells (Video-S2), confirming cellular uptake.

Next, we studied the capacity of AgNPs to modulate the release of cytokines in non-infected or Influenza-infected cells. In NCI-H292 cells, AgNPs alone stimulated the secretion of IL-8 in a dose dependent manner (Fig-2A), in agreement with previous reports showing a proinflammatory activity associated to AgNPs. ${ }^{21,22}$ Infection of NCI-H292 cells with Influenza (Flu cells) induced the release of CCL-5, IL-8 and IL-6 (Fig-2A), as previously described. ${ }^{23,} 24$ Interestingly, combination of Influenza and AgNPs resulted in the down-regulation of CCL-5 expression at protein (Fig-2A) and RNA levels (Fig-S2), whereas IL-8 and IL-6 levels were synergistically increased in these conditions (Fig-2A and Fig-S2). Using another bronchial and alveolar cell line (BEAS-2B and A549, respectively), we showed that although Influenza infection induced the release of CCL-5, IL-8 and IL-6 in both cells lines, treatment of infected cells with AgNPs only down-regulated the expression of Influenza-induced CCL-5 in BEAS-2B without significant changes in the expression of IL-8 nor that of IL-6 (Fig-2B). These data demonstrate that AgNPs are able to differentially modulate the production of pro-inflammatory 
(IL-8 and IL-6) and antiviral (CCL5) cytokines in different cells, as previously described in other models. ${ }^{8-10}$ Notably, AgNPs treatment of A549 cells did not modify the production of any of the cytokines studied (Fig-2C) although this cell line was as efficient as NCI-H292 and BEAS-2B in internalizing AgNPs (Fig-1), supporting the concept that different cell types may use different signalling pathways to sense viral infection. ${ }^{25}$

Because IFN- $\beta$ is a key regulator of antiviral immunity and because CCL-5 and IFN- $\beta$ share common signalling pathways, ${ }^{26,27}$ we also measured the production of IFN- $\beta$ in the supernatants of Influenza-infected NCI-H292 cells, treated or not with AgNPs. As shown Fig-2E, AgNPs reduced the release of IFN- $\beta$ in Influenza-infected cells. Importantly, down-regulation of CCL-5 and IFN- $\beta$ expression by AgNPs in Influenza-infected NCI-H292 cells was not related to increased cytotoxicity (Fig-2D) neither to changes in viral replication (Fig-2F). Next, we showed that, as in epithelial cell lines, AgNPs also reduced Influenza-induced CCL-5 release but not that of IL-8 in Influenza-infected cells in isolated primary lung epithelial cells from human lung specimens (Fig-2G).

Next, we showed that the reduction in Influenza-induced CCL-5 secretion was independent of the nanoparticle coating (citrate or lipoid acid), but was instead dependent on the silver core. The importance of the core was strengthened by the finding that gold nanoparticles (AuNPs) harbouring similar coatings did not modulate Influenza-mediated cytokine production (Fig-3). Interestingly, the presence of silver ions $\left(\mathrm{Ag}^{+}\right)$added to the culture media as silver nitrates also inhibited Influenza-induced CCL-5 release (Fig-3) and addition of L-cysteine reverted $\mathrm{Ag}+$ effect, suggesting that dissolution of the core of AgNPs (promoting Ag release) could partially mediate AgNPs effects. However, Ag+ in cellular extracts of AgNPs treated cells represented less 
than $5 \%$ of the AgNPs weight (Table-S1), suggesting that in our AgNP particle experimental model, the leaking of soluble $\mathrm{Ag}+$ could in fine unlikely explain the observed modulatory effects.

\section{AgNPs impair CCL-5 release in RIG-I dependent activated epithelial cells.}

In order to explore the mechanisms through which AgNPs down-regulate CCL-5 and IFN- $\beta$ in Influenza-infected epithelial cells, we analysed the signalling pathways underlying the expression of both cytokines. Preliminary experiments using a siRNA strategy showed that the MAVS/RIG-I signalling pathway was involved (data not shown). Next we generated CRISP/Cas9 RIG-I knockout clones from NCI-H292 cells to unequivocally demonstrate the importance of RIG-I in CCL-5 and IFN- $\beta$ production (Fig-S3). Ablation of RIG-I was confirmed both biochemically (as assessed by Western blot) and functionally, by demonstrating the absence of 5'3p-dsRNA (a RIG-I ligand)-dependent activation, but not that of polyIC (a TLR3 ligand, Fig-S3B). Following Influenza-infection, RIG-I KO cells produced no measurable CCL-5 or IFN- $\beta$ (Fig-S3C), and released less IL-6, while the production of IL-8 was barely affected. Importantly, abrogation of Influenza-induced CCL-5 production in RIG-I KO cells was not due to reduced viral replication nor to the intrinsic inability of the cells to produce CCL-5 (Fig-S3). These data clearly demonstrate that MAVS/RIG-I signalling pathway is absolutely required for the release of Influenza-induced CCL-5 and IFN- $\beta$ in our model, in agreement with previous data showing a key role of RIG-I as a viral sensor. ${ }^{18}$ Moreover, stimulation of NCI-H292 cells with the RIG-I ligand 5'3p-dsRNA induced CCL-5, and this could be inhibited by pre-treatment of cells with AgNPs (Fig-4A), strongly suggesting that AgNPs-down-regulates CCL-5 and IFN- $\beta$ production in Influenza-infected cells (Fig-2) by targeting the MAVS/RIG-I signalling pathway. Finally, to further demonstrate the specificity of action of AgNPs on the RIG-I signalling pathway, we 
showed that exposure of NCI-H292 cells to AgNPs did not reduce CCL-5 release, when stimulated with polyIC or with cGAMP (a ligand for STING, a receptor located at the endoplasmic reticulum membrane) (Fig 4B-C). Instead, AgNPs exposure even enhanced TLR-3dependent CCL-5 release (Fig-4B).

\section{Down-regulation of IFN- $\beta$ and CCL-5 by AgNPs during Influenza infection is independent of IRF-3, but depends upon IRF-7 activation.}

We next explored the consequences of AgNPs exposure on the activation of signalling pathways downstream of RIG-I, that includes TBK-1, Erk1/2 and Akt kinases. Influenza infection of NCIH292 cells resulted in TBK-1, Erk1/2 and Akt kinases activation (Fig-S4A), consistently with previous reports. ${ }^{28,29}$ Interestingly, AgNPs treatment reduced both 5'-3p-dsRNA- and Influenzamediated TBK-1 activation, suggesting a potential link between TBK-1 and AgNPs in terms of CCL-5 and IFN- $\beta$ modulation (Fig-4 A-B). However, Influenza virus still induced a robust CCL5 and IFN- $\beta$ release in NCI-H292-derived or BEAS-2B-derived TBK-1-KO clones, similarly to that observed in the WT parent cells (Fig-S4 C-D). In addition, AgNPs treatment reduced to the same extend CCL-5 and IFN- $\beta$ production in both TBK-1 KO and WT infected cells (Fig-S4 CD), ruling out TBK-1 as the 'kinase link' between RIG-I and CCL5/ IFN- $\beta$.

Next, we focused on the transcription factors of the interferon regulatory factors (IRFs) family because RIG-dependent activation of IRF-3 and IRF-7 has been demonstrated to induce IFNs and related cytokines in the context of viral infection. ${ }^{30,31}$ We generated both IRF-3 KO and IRF-7 KO clones from NCI-H292 cells and showed that IRF-3 KO infected cells released much less CCL-5, IFN- $\beta$ and IL-6, compared to WT cells (Fig-5A), while IL-8 release was instead enhanced in IRF-3-KO cells. As for IRF-3, IRF-7 KO cells were clearly impaired in their ability 
to produce IFN- $\beta$ and to a less extent CCL-5 in infected cells (Fig-5A). These data are consistent with previous reports showing that CCL-5 and IFN- $\beta$ expression is dependent of IRF-3 and IRF7. ${ }^{26,27}$ Moreover we demonstrate that CCL-5 and IFN- $\beta$ promoters (but not that of IL-8) are under the control of IRFs in our cell model, reflecting differential genetic regulation of IL-8 and CCL-5 promoters during Influenza infection ${ }^{32}$ that could explain the dichotomy in AgNP-induced CCL-5/IFN- $\beta$ and IL-8 modulation described above (Fig-2).

However, interestingly, AgNPs did not inhibit Influenza-induced IRF3 dimerization (a gold standard to measure IRF-3 activation) (Fig-S5), suggesting that IRF-3 was likely not the target of AgNPs-mediated events. Importantly, although AgNPs still down-regulated Influenza-induced CCL-5 and IFN- $\beta$ release in IRF-7 KO clones (Fig-5B), the extent of the inhibition was clearly reduced in $\mathrm{KO}$ cells compared to WT clones (Fig-5C), indicating that IRF-7 was at least partly impacted by AgNPs during release of CCL- 5 and IFN- $\beta$ in Influenza-infected cells. Moreover, enhancement of Influenza-induced IL-8 and IL-6 secretion by AgNPs was similar in IRF-7 KO and wild-type cells (Fig-5C), showing specificity of AgNPs for the IRF7/CCL5-IFN $\beta$ signalling pathway. One possible explanation for the preferential activity of AgNPs on IRF-7 (and not on IRF-3) could be related to the constitutive expression of IRF-3 in NCI-H292 cells (Fig-S5). By contrast, IRF-7 is up-regulated only after Influenza infection (see below), as described in other cell types. ${ }^{31}$ Whereas activation of IRF-3 should be critical in the early phases of viral replication, IRF-7 will likely play a role later, at a time point when the internalization of AgNPs (Fig-1) will have already triggered the reorganization of the mitochondrial network (see below). 


\section{AgNPs modify the distribution of the mitochondrial network in basal and RIG-I-dependent activated epithelial cells.}

Considering that i) AgNPs specifically altered the RIG-I signalling pathway (Fig-4) which activation depends on the association of RIG-I with MAVS at the mitochondrial membrane, ${ }^{19}$ ii) mitochondrial dynamics is a key factor modulating signalling pathways conducting to TBK-1 and IRFs activation $^{30}$ and interferon release ${ }^{33}$ during viral infections, iii) AgNPs cytotoxicity has been associated to alterations in mitochondria, ${ }^{11,12}$ we explored the possibility that AgNPs may induce changes in the mitochondrial network of lung epithelial cells in the context of viral infection. Coupling dark-field with fluorescence microscopy (using MitoTracker ${ }^{\circledR R e d ~ C M X R o s, ~ t o ~ s t a i n ~}$ mitochondria in live NCI-H292 cells and LysoTracker ${ }^{\circledR}$ Green to stain acidic compartments), we showed that AgNPs altered mitochondrial organisation/mitochondrial membrane potential, resulting in a more "aggregated" network (Fig-6). Interestingly, some of the internalized AgNPs co-localized with acidic compartments (white arrows), which were increased in numbers, and vacuolisation of the cytoplasm was clearly observed. Because of biosafety limitations placed upon this experimental set-up, 5'3p-dsRNA was used as an Influenza-surrogate for RIG-I stimulation. On its own, 5'3p-dsRNA slightly modulated the mitochondrial network, but that modulation was dramatically enhanced post AgNPs administration, with a clear 'aggregation' of mitochondria in that network. Furthermore, increased numbers of acidic compartments (containing or not AgNPs) were often found surrounded by mitochondria clogs (Fig-6, white arrows). 


\section{AgNPs alter the autophagic flux in lung epithelial cells, leading to reduced IFN- $\beta$ and CCL-}

\section{5 secretion.}

Because increased vacuolisation of the cytoplasm (Fig-6) and alterations of the mitochondrial network (Fig-6) are a hallmark of autophagy, ${ }^{14}$ we then investigated whether AgNPs could modify the autophagy flux in lung epithelial cells as shown recently in a different context. ${ }^{13}$ Preliminary data demonstrated that inhibition or blockade of autophagic flux in lung epithelial cells reduced Influenza induced CCL-5 secretion (Fig-S6), indicating that autophagic flux regulates Influenza-induced responses. Next, transmission electron microscopy (TEM) images of NCI-H292 cells treated with AgNPs alone showed cytoplasmic multi-vesicular vacuoles (Fig-7A, Fig-S7) containing AgNPs-like structures (black arrows). Moreover, AgNPs treatment alone increased the expression LC3-I and its conversion to LC3-II (a known marker of autophagosomes), concomitant to the detection of increased levels of the cargo-associated protein p62 as showed Western Blot analysis (Fig-7B). Since p62 accumulates when the autophagy flux is blocked, our results indicate that AgNPs likely block that flux in NCI-H292 cells. Importantly, gold nanoparticles (AuNPs) that did not modify Influenza-induced CCL-5 secretion (Fig-3) failed to modify LC3 expression (Fig-7B). Moreover, silver salts (Ag+) that impaired Influenzainduced CCL-5 secretion (Fig-3), increased LC3 expression but did not promote its conversion to LC3-II neither p62 accumulation (Fig-7B), suggesting that mechanisms of action of Ag+ differ from that of AgNPs in terms of down-regulation of IFN-related signalling pathways during Influenza infection. These data, in addition to the poor detection of Ag+ in cell extracts of AgNPs treated cells (Table-S1), support that Ag+ release from the nanoparticle does not recapitulate all the activity associated to Ag particle in our model. Notably, AgNPs also blocked the autophagic flux in Influenza-infected NCI-H292 cells (Fig-7C). Consistently, confocal microscopy 
confirmed that AgNPs treatment increased both number and size of LC3 positive vesicles (autophagosomes) in the cytoplasm of both non-infected and Influeza-infected NCI-H292 cells (Fig-7D, Fig-S8). These LC3+ autophagosomes were found in close contact with Tom20 (a translocase of the mitochondrial outer membrane that monitors mitochondrial network) and some of them contained AgNPs-like structures as observed from bright field merged images (Fig-7D, white arrows). These data clearly show that the blockade of the 'classical' autophagic flux by AgNPs in infected NCI-H292 cells favours the accumulation of mitochondrial compounds in LC3+ autophagosomes. This is consistent with the observed alteration of the mitochondrial network (Fig-6), and therefore imply causality between AgNPs-mediated blockade of autophagy (Fig 7A-D) and alterations of the mitochondrial network (Fig-6).

Considering the alterations of the mitochondrial network induced by AgNPs (Fig-6, Fig-7) and the role of mitochondria as a platform for IRF activation, ${ }^{30}$ we hypothesized that AgNPs could impact upon the distribution of IRF-7 (a target of AgNPs in NCI-H292 cells (Fig-5)).

Indeed, Western Blot analysis showed that Influenza infection up-regulated IRF-7, which was detected in the cytosolic, mitochondrial and nuclear fractions (Fig-7E). AgNPs treatment of Influenza-infected cells resulted in enhanced expression of IRF-7 in the cytosol and mitochondrial fractions compared to those from non-treated Influenza-infected cells. By contrast, IRF-7 expression was reduced in the nuclear fraction following AgNPs treatment of infected cells (Fig-7E). This distribution was confirmed by confocal microscopy, with IRF-7 expression in Influenza-infected cells (Fig-7F) but not in non-infected cells (Fig-S9). Furthermore, distribution of IRF-7 in the cytoplasm was more homogeneous in Influenza-/alone infected cells than in Influenza-/AgNPs cells. Indeed, IRF-7 localisation was polarized in Influenza/AgNPs-treated cells, in a lattice-like structure associated with the mitochondrial network (Fig-7F). 
Because changes in the mitochondrial dynamics modulate RIG-I-dependent signalling pathways ${ }^{33}$ our findings that AgNPs modulate both the mitochondrial network (Fig-6) and the RIG-I/IRF7 signalling pathway (Fig-4 and Fig-5) in the context of viral infection strongly suggest that these two events are linked in NCI-H292 cells and mediate the observed down-regulation of antiviral defences (production of CCL-5 and IFN- $\beta$ ) (Fig-2).

However, we showed that the mechanisms involved may be different in BEAS-2B cells, another lung epithelial cell type studied here (Fig-2B, Fig-3, Fig-S4D).

Indeed, although AgNPs also modulated Influenza-induced CCL-5 and IFN- $\beta$ secretion in BEAS-2B cells (Fig-2), AgNPs exposure did not enhance LC3 expression (Fig-8A) nor the numbers of LC3 + autophagosomes (data not shown) in non-infected or Influenza-infected BEAS2B cells, contrary to NCI-H292 cells. Because this could potentially be explained by an absence of the 'classical' ATG5-LC3-mediated autophagy machinery in BEAS-2B cells, we performed experiments with chloroquine, an inhibitor of phagosome-lysosome fusion (thus a chemical blocker of the autophagic flux). We showed that chloroquine enhanced LC3-II accumulation in WT (but not in ATG-5KO) BEAS-2B cells (Fig-8A), indicating that ATG-5 dependent autophagy (mediating LC3-I conversion to LC3-II) is functional in BEAS-2B cells, even though, as shown above, while effective in NCI-H292 cells, AgNPs did not alter this pathway in BEAS2B cells. However, because AgNPs still altered the mitochondrial network in BEAS-2B cells similarly as in NCI-H292 cells, we sought to investigate if AgNPs influenced the alternative autophagic pathway (independent of ATG-5 and LC3 lipidation) characterized by accumulation of Rab9+ autophagosomes. ${ }^{16}$ Consistently, confocal microscopy showed that AgNPs clearly enhanced the size and number of Rab9+ vesicles in non-infected and also in Influenza-infected BEAS-2B cells (Fig-8B, Fig-S10), in contrast to control cells which presented smaller Rab9+ 
vesicles. Interestingly, superposed fluorescence and bright field images showed that Rab9+ autophagosomes contained AgNPs-like structures in BEAS-2B cells (Fig-8B, white arrows). In addition, we also observed an increase in the size and number of Lamp- 2 positive vesicles in Influenza-infected cells (Fig-8B, Fig-S10), consistent with activation of alternative autophagic flux. ${ }^{16}$ To further determine whether AgNPs were targeting the alternative autophagic pathway in BEAS-2B cells (thereby down-regulating CCL-5 and IFN- $\beta$ release in infected cells), we incubated Influenza-infected BEAS-2B cells with AgNPs in the presence of 3-MA, an inhibitor of both alternative and conventional/ATG-5-dependent autophagy pathways. ${ }^{16}$ To rule out activation of 'parasite' ATG-5-dependent 'classical' autophagy, we performed these experiments in BEAS-2B ATG-5 KO, and showed that 3-MA down-regulated in a dose dependent manner Influenza-induced CCL-5 and IFN- $\beta$ secretion in both ATG-5 WT and ATG-5 KO (Fig-8C), although $\mathrm{KO}$ cells were more resistant to 3-MA inhibition (probably because of the absence of a functional ATG-5 dependent autophagy pathway). Notably, differences between AgNPs-treated infected cells and vehicle-treated infected cells in terms of CCL-5 and IFN- $\beta$ secretion were reduced when 3-MA concentration increased (Fig-8D), indicating that inhibition of alternative autophagy (operative in ATG5 BEAS-2B KO cells) with 3-MA abolishes the biological effect of AgNPs on Influenza-induced CCL-5 and IFN- $\beta$ secretion. 


\section{CONCLUSIONS}

Although previous studies have described that AgNPs could alter the autophagic flux in lung epithelial cells, a phenomenon associated to cytotoxicity, ${ }^{34}$ the physiological consequences of autophagy modulation had not been described so far. Here we described that AgNPs modulate both Rab9-dependent alternative (in BEAS-2B cells) as well as ATG-5-dependent classical autophagy (in NCI-H292 cells) and in doing so down-regulate antiviral responses in lung epithelial cells, while, conversely, up-regulating a neutrophilic pro-inflammatory response (as exemplified by the use of IL-8 read-out in our study). In order to extrapolate the consequences of AgNP exposure on lung epithelial cells in Influenza animal models and more importantly to elucidate whether AgNP effects are mediated through autophagy in these models, several issues may be discussed. First, we must consider the bio-distribution of AgNPs after in vivo lung delivery. It has been shown that pulmonary delivery of AgNPs in rats targets resident cells like alveolar macrophages ${ }^{35}$ and probably lung epithelial cells as deduced from in vitro ${ }^{36}$ models and in vivo lung delivery of other nanoparticles. ${ }^{6}$ Consequently, considering our data, AgNPs could alter autophagic flux in both uninfected and infected lung epithelial cells in vivo. Secondly, the role of autophagy in influenza infection is the subject of on-going debate. Whereas in vitro data indicate that autophagy pathway mediates Influenza virus replication and viral-induced apoptosis,

37 it is uncertain whether manipulation of the autophagic flux during Influenza infection might result beneficial or deleterious for the resolution of the infection since blockers of autophagic flux, could inhibit viral replication. ${ }^{38,39}$ In consequence, it may be expected that targeting infected lung epithelial cells with AgNPs (which blocks autophagy) could reduce viral replication. However, our data show that the blockade of the autophagic flux with AgNPs does not inhibit viral replication in already infected cells. Moreover, inhibition of autophagy initiation 
by administration of 3-MA to infected mice ameliorates lung injury associated to Influenza infection, especially with pandemic strains. ${ }^{40}$ Furthermore, pandemic flu has been associated to excessive lung inflammation ('cytokine storm'), with, as a consequence, reduced viral clearance and secondary bacterial infections. ${ }^{41,42}$ Our data, with a clear focus on lung epithelial cells, suggest that administration of AgNPs in infected animals could enhance inflammation (neutrophil recruitment through IL-8-dependent mechanisms) and down-regulate interferon-pathways, with detrimental consequences for the host due to unbalanced inflammation/anti-viral responses. Another possible therapeutic option may consist in administrating AgNPs as a prophylactic drug in order to i) block the autophagic flux in non-infected cells thus preventing viral replication; ii) take advantage of the pro-inflammatory properties of AgNPs to boost lung innate immunity. Finally, it is important to consider that leukocytes, especially alveolar macrophages also participate to early anti-influenza responses ${ }^{43}$ and that this cell type is a target for pulmonary delivered AgNPs. ${ }^{35}$ Moreover, it has been shown that AgNPs block the autophagic flux in monocyte-derived macrophages in vitro. ${ }^{44}$ Altogether, these data indicate that in vivo administration of AgNPs could also modulate alveolar macrophage anti-viral defences through autophagy.

In conclusion, AgNPs may be a fascinating tool for the biasing of anti-microbial immunity especially during co-infections where it has been shown that INF- $\beta$ produced during viral infection down-regulates anti-bacterial defences, enhancing susceptibility to secondary bacterial infections. ${ }^{45}$ At optimal doses, AgNPs might reduce INFs production while enhancing antibacterial defences. 


\section{MATERIALS AND METHODS}

\section{Nanoparticle characterization.}

10nm silver (Ag) or gold (Au) nanoparticles (NPs) were purchased from NanoComposix USA (San Diego, CA) or NanoComposix Europe (Prague, Czech Republic). NPs were produced at BioPure quality with citrate (Cit) or lipoic acid (La) as a coating agent. Cit-NPs and La-NPs were resuspended in a $2 \mathrm{mM}$ sodium citrate solution and water, respectively, at a final concentration of $1 \mathrm{mg} / \mathrm{ml}$. Each batch was characterized by the manufacturers in terms of static and hydrodynamic diameters, zeta potential and endotoxin content (Table-1). Static and hydrodynamic diameters were determined by transmission electron microscopy (TEM) (JEOL 1010 Transmission Electron Microscope) and dynamic light scattering (DLS) (Malvern Zetasizer Nano ZS), respectively. Charge of NPs was determined by zeta potential (Malvern Zetasizer Nano ZS). Endotoxin (LPS) content was measured by the Limulus amebocyte lysate (LAL) assay by the kinetic turbidity mode at doses of NPs that did not interfere with the assay. Each batch of NPs included representative images of TEM and graphs representing size distribution (relative \% vs. particle diameter) and optical properties (absorbance vs. wavelength) (Fig-S1). Final mass concentration of Ag and Au was determined by Inductively Coupled Plasma Mass Spectrometry (ICP-MS) in a Xseries 2 ICP-MS (Thermo Fisher) and spectral properties were recorded in a Agilent 8453 UVvisible spectrophotometer (Agilent). Nanoparticles were stored at $4{ }^{\circ} \mathrm{C}$ protected from light for no more than one year after reception. Four independent batches of Cit-AgNPs and La-AgNPs, 2 of La-AuNPs and 1 of Cit-AuNPs have been used in the study. 


\section{Influenza virus}

Virus strain A/Scotland/20/74 (H3N2) was a gift from Professor van der Werf (Institut Pasteur, Paris). Virus was routinely amplified in MDCK cells (ATCC CCL-34). Supernatants of infected or not infected cells (mock) were aliquoted and kept at $-80^{\circ} \mathrm{C}$ until use. Plaque forming units (PFU/ml) of Influenza stocks were quantified by the virus plaque assay.

\section{Virus plaque assay}

MDCK cells were grown until confluency in P6 well plates in MEM medium containing glutamine, antibiotics and 5\% fetal calf serum. Then, 1/10 serial dilutions of conditioned medium from either Influenza stocks or infected cells (NCI-H292) were added to the cells and incubated for $1 \mathrm{~h}$ at $37^{\circ} \mathrm{C}$ in a humidified incubator. TPCK-trypsin (Worthington) $(1 \mu \mathrm{g} / \mathrm{ml}$ final concentration) and Avicel microcrystalline cellulose (1.2\% w/v) (FMC Biopolymer) were then added and infected monolayers were incubated for $48 \mathrm{~h}$. After washing, cell monolayers were stained with crystal violet and lysis plaques (pfu) were counted.

\section{Cell lines}

NCI-H292 cells (ATCC reference number CRL-1848), a human pulmonary mucoepidermoid carcinoma cell line, BEAS-2B cells (ATCC CRL-9609), a SV-40 transformed bronchial epithelial cell line and A549 (ATCC CCL-185) a cell line from a lung adenocarcinoma, were cultured in RPMI (NCI-H292) or F12/K Nutrient mixture (BEAS-2B and A549) medium supplemented with Glutamax, antibiotics and 10\% decomplemented fetal calf serum (all reagents from Gibco). Cells were incubated at $37^{\circ} \mathrm{C}$ in a water-jacketed $\mathrm{CO} 2$ incubator. 


\section{Primary lung epithelial cells.}

Human lung tissues were obtained from patients (after written consent) who had undergone surgery for lung carcinoma (Ethics Committee and Institutional Review Board No. IRB00006477, agreement No. 11-045) as described before. ${ }^{46}$ Primary human lung epithelial cells were obtained from lung sections from healthy regions following a protocol based on previous studies. ${ }^{47,48}$ Briefly, lung sections were cut in small pieces and incubated for $1 \mathrm{~h}$ at $37^{\circ} \mathrm{C}$ in dispase (5.0000 casenolytic units in 100ml, BD Biosciences) followed by additional $10 \mathrm{~min}$ in the presence of $0.01 \%$ DNase I (Sigma). Next, lung homogenate was sequentially filtered through mesh gauze and cell strainers $(100 \mu \mathrm{m}$ and $40 \mu \mathrm{m})$. Then cells were spin down and panned in 10 $\mathrm{cm}$ Petri dishes ( $\approx 20$ millions of cells/dish) for $1-2 \mathrm{~h}$ at $37^{\circ} \mathrm{C}$ in a water-jacketed $\mathrm{CO} 2$ incubator in DMEM media supplemented with $10 \%$ FCS. Non-adherent cells were collected, spun down and separated in 60\%-30\% discontinuous Percoll gradient. Epithelial-enriched fraction (30\% Percoll) was collected and washed. Cells were cultured in Biocoat p24 well plates (BD Biosciences) in F12/K medium supplemented with Glutamine, antibiotics and 10\% FCS and were kept in culture until day 4-5 to obtain a confluent monolayer. Purity of preparations was assayed by immunofluorescence using rabbit anti-pro surfactant protein C (SP-C) (Merck Millipore), rabbit anti zona occludens 1 (ZO1) (Invitrogen), guinea-pig anti-pan cytokeratin (CK) (Progen Biotechnik, Germany), and the corresponding secondary antibodies (Invitrogen). Cells showed over $95 \%$ of $\mathrm{CK}$ and $\mathrm{ZO} 1$ positive cells confirming epithelial origin. Rat alveolar type II epithelial cells were isolated as described previously. ${ }^{49}$ 


\section{Generation of KO cell lines}

Semi-confluent NCI-H292 cells or BEAS-2B cells grown onto p6 well plates were transfected with a pool of three specific CRISPR/Cas9 Knockout (KO) plasmids encoding the Cas9 nuclease and a specific $20 \mathrm{nt}$ guide RNA for the indicated gene (RIG-I, TBK-1, IRF-3, IRF-7 or ATG-5) and a pool of 3 plasmids, each containing a homology-directed DNA repair (HDR) template corresponding to the sites generated by the CRISPR/Cas9 KO plasmids and able to insert a puromycin resistance gene for selection of stable $\mathrm{KO}$ cells. All plasmids were purchased from Santa Cruz Biotechnology, Germany. Transfection was performed at different plasmid/lipofectamine (Life Technologies) ratios in Opti-MEM medium (Life Technologies) for 8h. Then, transfection medium was replaced by cell culture complete medium and cells were kept for $72 \mathrm{~h}$ in culture. Cells were thereafter trypsinized and transfered to $10 \mathrm{~cm}$ petri dishes in complete cell culture medium supplemented with puromycin (InvivoGen) $(2 \mu \mathrm{g} / \mathrm{ml}$ for NCI-H292 and $1 \mu \mathrm{g} / \mathrm{ml}$ for BEAS-2B). Next, clones were collected (Sigma cloning cylinders) and amplified and the absence of the target protein was confirmed by Western blot. Clones that incorporated the puromycin resistance cassette but kept normal levels of expression of the target protein ('failed KOs') were used as wild-type (WT) control cells.

\section{Stimulation of cell cultures.}

Cells were washed three times with serum free media and then infected in serum free media with Influenza (Influenza A/Scotland/20/74 (H3N2) at indicated MOI (Multiplicity of Infection = number of PFU added per cell). 1h-2h later (after allowing viral entry), cells were washed and NPs added at the indicated concentrations $\left(2-5 \mu \mathrm{g} / \mathrm{ml}\right.$ equivalent to $\left.0.66-1 \mu \mathrm{g} / \mathrm{cm}^{2}\right)$ for $18 \mathrm{~h}$ (unless otherwise stated) in the same media. In other set of experiments, cells were treated with 
silver nitrate, L-Cysteine, Chloroquine or 3-MA (3-Methyladenine) at indicated concentrations (all products from Sigma). In selected experiments, cells were first exposed to NPs for 5h, washed and then treated with either Influenza virus (Flu), 5' triphosphate double stranded RNA (5’3p-dsRNA at $1.2 \mu \mathrm{g} / \mathrm{ml}$ ) (Invivogen), complexed to lipofectamine 2000 (Invitrogen), with polyinosinic-polycytidylic acid (poly IC at $10 \mu \mathrm{g} / \mathrm{ml}$ ) (Sigma or Invivogen) or with cyclic [G(2',5')pA(3',5')p]) (cGAMP at $10 \mu \mathrm{g} / \mathrm{ml})$ (Invivogen). Then, complexes were added to a p24 well of confluent cells containing $200 \mu \mathrm{l}$ of the same medium. After $18 \mathrm{hr}$, supernatants were collected and kept at $-20^{\circ} \mathrm{C}$ or $-80^{\circ} \mathrm{C}$ until concentrations of cytokines were measured. In parallel, cells were lysed in RNA extraction buffer (Pure-Link, Thermo Fisher) for RNA assessment. In selected experiments, BEAS-2B cells were grown onto Biocoat p24 well plates to increase adherence.

\section{Viral replication}

Viral replication in infected cells was measured by plaque assay (see above), RT-qPCR (M2 expression, see below) or by measuring viral nucleoprotein levels in supernatants of infected cells by ELISA. Briefly, serial dilutions in carbonate buffer of supernatants were seed in 96-well plates overnight at $4{ }^{\circ} \mathrm{C}$. After blocking $(2 \%$ BSA), wells were incubated with mouse anti-Influenza nucleoprotein antibody (Santa Cruz) in PBS, 1\% BSA 0,05\% Tween-20 buffer for $2 \mathrm{~h}$. After washing, wells were incubated with anti-mouse IgG antibody coupled to HRP. HRP was detected after addition of TMB substrate and measure of O.D. at 450nm. A standard, consisting in purified Influenza virus, was included to correlate quantity of NP with known $\mathrm{pfu} / \mathrm{ml}$. 


\section{Concentration of cytokines}

Concentrations of cytokines in supernatants of cell cultures were quantified by sandwich ELISA kits following the manufacturer's indications (Bio-Techne) for all cytokines except for IFN- $\beta$ (VeriKine kits from PBL Assay Science).

\section{Concentration of Ag+ in cellular extracts.}

Non-infected or infected NCI-H292 cells $\left(10 \times 10^{6}\right)($ MOI 0.25) were incubated with Cit-AgNPs or La-AgNPs $(5 \mu \mathrm{g} / \mathrm{ml})(50 \mu \mathrm{g}$ total amount of AgNPs per condition) for $18 \mathrm{~h}$ in $10 \mathrm{ml}$ of serum-free RPMI. After washing, cells were trypsinized and concentrated by centrifugation. Pellet was resuspended in $1 \mathrm{ml}$ of lysis buffer $(1 \%$ Triton $\mathrm{X}-100$ in $150 \mathrm{mM} \mathrm{NaCl})$ and incubated at $4{ }^{\circ} \mathrm{C}$ for 30 minutes with intermittent vortexing. In parallel the same amount of input AgNPs $(50 \mu \mathrm{g})$ was resuspended in $1 \mathrm{ml}$ of lysis buffer and treated as cell lysates. Next, AgNPs and cell lysates were centrifuged to precipitate intact NPs and cell debris $\left(16000 \mathrm{~g}, 30 \mathrm{~min}, 4^{\circ} \mathrm{C}\right)$. Supernatants $(\approx 1 \mathrm{ml})$ were diluted to $10 \mathrm{ml}$ with ultrapure deionized water and the concentration of solubilized $\mathrm{Ag}^{+}$ ions were probed by an inductively coupled plasma optical emission spectrometer (ICP-OES) (Varian Vista Pro) with a plasma temperature between 8000 and $9000^{\circ} \mathrm{C}$. The spectrometer presented an optimized axially viewed plasma system with a VistaChip CCD detector, allowing continuous wavelength coverage and simultaneously measure of both trace and major concentrations of $\mathrm{Ag}+$ with a detection limit of $0.3 \mathrm{ug} / \mathrm{L}$. Quantification was performed using a calibration curve. The matrix for the analysis consisted of $1 \mathrm{ml}$ of lysis buffer and $9 \mathrm{ml}$ of water. Lysates from non-treated cells were included to measure background levels of $\mathrm{Ag}^{+}$in the absence of AgNPs. 


\section{RNA Extraction and RT-qPCR}

Cell monolayers were directly lysed in RNA lysis buffer. For RNA isolation, steps were performed according to the manufacturer's instructions. The corresponding cDNA was synthesised using random hexamers (Roche) and M-MLV reverse transcriptase (Promega). Realtime PCR was performed in 7500 Fast Real-Time PCR System (Applied Biosystems) using the Fast SYBR Green Master Mix (Applied Biosystems). The primers used were the following: M2 viral protein (Fw aagaccaatcctgtcacctct; Rw:caaagcgtctacgctgcagtc), CCL-5 (Fw: cagtcgtctttgtcacccgaa; Rw： tcccaagctaggacaagagca), IL-8 (Fw:agagacagcagagcacacaa; Rw:ttagcactccttggcaaaac), IL-6 (Fw:tcaatgaggagacttgcctg; Rw:tgtactcatctgcacagcctc), HPRT (Fw:ttgctttccttggtcaggca; Rw :atccaacacttcgtggggtc), 18s rRNA (Fw:cttagagggacaagtggeg; $\mathrm{Rw}$ : acgetgagccagtcagtgta). Triplicate $\mathrm{Ct}$ values were analysed using the comparative $\mathrm{Ct}(\Delta \Delta \mathrm{Ct})$ method. The amount of target (2- $\Delta \Delta \mathrm{CT})$ was calculated using control cells as calibrator (arbitrary units $=1$ ) and HPRT or 18s rRNA as the house keeping gene.

\section{Mitochondrial extractions}

$20 \times 10^{6}$ of unstimulated or stimulated/infected NCI-H292 cells were scrapped in cold PBS buffer and pelleted by centrifugation $\left(400 \mathrm{~g}, 4^{\circ} \mathrm{C}, 10 \mathrm{~min}\right)$. Then, cells were resuspended in $1 \mathrm{ml}$ of mitochondrial isolation buffer I (10mM HEPES pH 7.5, 250mM saccharose, 1mM EDTA), supplemented with protease-inhibitor cocktail EDTA-free and phosphatase-inhibitor cocktail (Roche). The pellet was then disrupted on ice with a in a teflon pestle homogenizer, with three cycles of freezing (liquid nitrogen $15 \mathrm{~s}$ ) and thawing at $37^{\circ} \mathrm{C}$. Nuclei fractions were separated by centrifugation $\left(1200 \mathrm{~g}, 10 \mathrm{~min}, 4^{\circ} \mathrm{C}\right)$ and then the cytosolic and mitochondrial rich fractions were separated by further centrifugation $\left(16000 \mathrm{~g}, 30 \mathrm{~min}, 4^{\circ} \mathrm{C}\right)$. The pellet containing the 
mitochondrial-rich fraction was then resuspended in mitochondrial isolation buffer II (buffer I without saccharose). Nuclear proteins were solubilized in RIPA buffer (see below) and total protein in each fraction was quantified by Micro BCA method (Pierce).

\section{Electrophoresis and Western blotting}

Cells lysed in RIPA buffer (25mM HEPES pH 7.5, 150mM NaCl, 5mM EDTA, 0.1\% SDS, 1\% NP-40, 0.5\% sodium deoxycholate) supplemented with protease-inhibitor cocktail EDTA-free (Roche) and phosphatase-inhibitor cocktail (Roche) were electrophoresed in SDS-PAGE gels and blotted in polyvinylidene fluoride (PVDF) membranes. For native gels (analysis of IRF3 dimers) cells were lysed in native lysis buffer $(50 \mathrm{mM}$ Tris- $\mathrm{HCl} \mathrm{pH} 7.5,150 \mathrm{mM} \mathrm{NaCl}, 1 \%$ IGEPAL) supplemented as above, and electrophoresed in PAGE without SDS nor reducing agents and adding $0.5 \%$ of sodium deoxycholate in the cathode chamber buffer. After transfer and blocking of the membrane (5\% skim milk in PBS pH 7.4), either of the following primary antibodies in blocking buffer containing $0.05 \%$ Tween-20 were added (overnight incubation at $4{ }^{\circ} \mathrm{C}$ ): anti-RIGI, anti-TBK1, anti-MDA5, anti-IRF3, anti-IRF7, anti phospho-p44/42 (ERK), anti-p44/42, antiphospho Akt, anti-Akt, anti-LC3, anti-p62 (all raised in rabbit from Cell Signalling and used at 1/1000 dilution); mouse anti-COX4 (Cell Signalling) (1/2000), mouse anti- $\beta$-tubulin (MerckMillipore) (1/10000), mouse anti-GAPDH (Covalab) (1/10000), mouse anti-Lamin A/C (1/1000) (Abcam). After incubation with the corresponding HRP-labelled secondary antibodies (Jackson Laboratories) (1/5000), chemiluminescence was developed using Clarity ECL substrate (BioRad) or Luminata (Thermo Fisher) and recorded in a PXi gel imaging system (Syngene). 


\section{Cell viability}

Lactate dehydrogenase (LDH) release was detected by measuring LDH activity in cell lysates and supernatants, using the CytoTox 96 Nonradioactive Cytotoxicity assay (Promega). Cell viability was also accessed by a resazurin (Sigma) reduction assay as described previously. ${ }^{50}$

\section{Confocal Fluorescence microscopy}

Cells grown onto coverslips coated with rat-tail collagen (Sigma) were fixed with methanol (10 min at $-20^{\circ} \mathrm{C}$ ) for LC3 detection or in $2 \%$ PFA-PBS buffer (10 min room temperature). After blocking with buffer assay (1\% BSA, $0.2 \%$ Triton-X100 in PBS pH 7.4), cells were incubated overnight at $4{ }^{\circ} \mathrm{C}$ with the following antibodies or combinations: rabbit anti-LC3 antibody, rabbit anti-Rab9 (both from Cell Signalling), mouse anti-Tom20 antibody, rabbit anti-Tom20 antibody, mouse anti-IRF7 antibody (all from Santa Cruz Biotechnology). This was followed by the corresponding secondary antibodies i.e. anti-rabbit AlexaFluor-555 coupled and anti-mouse AlexaFluor-488 coupled secondary antibody (Invitrogen) (1/2000, $2 \mathrm{~h}$ at room temperature). In selected experiments, anti-LC3 A555-coupled antibody and anti-Tom20 A488-coupled antibody were used. Nuclei were stained with DAPI (Invitrogen) and the preparations were mounted with Vectashield mounting media (Dako). Confocal images were acquired in a LSM 780 confocal microscopy (Zeiss) and were analysed and merged with Image J programme. Image acquisition and image analysis were performed in the Cri U1149 Imaging Facility. 


\section{Dark-Field and fluorescence Imaging}

Cells grown onto coverslips were treated with the indicated nanoparticles $(5 \mu \mathrm{g} / \mathrm{ml})$ for $5 \mathrm{~h}$ or $18 \mathrm{~h}$. In selected experiments cells were treated with 5’3p-dsRNA $(1.2 \mu \mathrm{g} / \mathrm{ml})$ for $3 \mathrm{~h}$. After washing, living cells were loaded with LysoTracker ${ }^{\circledR}$ Green DND-26 (20nM) and MitoTracker® Red CMXRos (250nM) (Molecular Probes) for $30 \mathrm{~min}$ at $37^{\circ} \mathrm{C}$. After washing, an upright Richardson RTM 2.5 microscope (Improvision, Tübingen, Germany) was used for combined dark-field and fluorescence imaging as described before. ${ }^{49}$ Dark-field and fluorescence light were detected with a 3CCD color video camera (ExwaveHAD DXC-C33, Sony; supplied by Improvision, Germany). All images were acquired with the $63 \times$ Leica water immersion objective (numerical aperture $=0.90$ ) and Micro-Manager software. ${ }^{51}$ Pixel aspect ratio was corrected to D1/DV NTSC 0.91 in Photoshop CC 2015 software. For fluorescence imaging the RTM 3.0 blue filter cube [490 $\mathrm{nm}$ dichroic, 400-500 nm excitation filter, 510 long-pass (LP) emission filter] and green filter cube [560 $\mathrm{nm}$ dichroic, 540-550 nm excitation filter, 570 LP emission filter] were used for all fluorescence experiments. Images were adjusted for brightness and contrast in Photoshop CC. For LTG images the green channel of RGB image is shown. Images were merged using ImageJ software.

\section{Transmission electron microscopy (TEM)}

Control or treated La-AgNPs treated NCI-H292 cells $(18 \mathrm{~h})\left(5 \mu \mathrm{g} / \mathrm{ml}, 0.88 \mu \mathrm{g} / \mathrm{cm}^{2}\right)$ were fixed with 1\% glutaraldehyde and 2,5\% paraformaldehyde in PBS buffer and post-fixed with 1\% osmium tetroxide and 1,5\% potassium ferrocyanide. Samples were then dehydrated through a gradual series of ethanol washes and embedded in epoxy resin. Ultrathin $(70 \mathrm{~nm})$ sections (Ultracut UC6, Leica) were collected on formvar/carbon-coated copper grids. Samples were 
observed in a Tecnai12 (FEI, The Netherlands) transmission electron microscope at $80 \mathrm{kV}$ equipped with a $1 \mathrm{~K} \times 1 \mathrm{~K}$ Keen View camera.

\section{Statistical analysis}

Data were expressed as means \pm standard errors of the mean (SEM) unless stated. ANOVA was used to determine statistically significant differences among groups followed by Tukey's multiple test for paired comparisons. All analyses were performed with Prism version 7, GraphPad.

\section{ACKNOWLEDGEMENTS}

This work was supported by "Legs Poix" Chancellerie des Universités de Paris and the National Agency of Research (ANR-13-JS10-0007-01). We also thank Dr Leeyah Issop (Inserm U1148, Bichat Hospital) for her help in setting up protocols to isolate mitochondria. Authors also acknowledge the Departments of "Thoracic and vascular Surgey" and "Pathology" (Bichat Hospital) for collection of lung specimens and Samira Benada of the CRI -U1149 imaging facility.

\section{COMPETING FINANCIAL INTERESTS}

Authors have no conflicts of interest to declare. 


\section{TABLES}

Table-1. Characterization of nanoparticles. The physicochemical properties (obtained from the manufacturers) of one representative batch of nanoparticles from NanoComposix are shown. Static and hydrodynamic diameters, ionic charge and endotoxin (LPS) content were determined as explained in the Materials and Methods section. n.r. = Not reported. Each batch also included representative images of TEM and a graph representing size distribution (relative\% $\% s$. particle diameter) and optical properties (absorbance vs. wavelength) (Fig-S1).

\section{FIGURE LEGENDS}

Fig-1. Nanoparticles with different coatings are equally internalised in lung epithelial cells. The indicated epithelial cell lines were incubated during $18 \mathrm{~h}$ with $5 \mu \mathrm{g} / \mathrm{ml}$ of citrate coated- (CitAgNPs), lipoic acid coated-(La-AgNP) or lipoic acid coated- gold nanoparticles (La-AuNPs). After washing, living cells were imaged by dark-field microscopy in a Richardson RTM 2.5 microscope. Representative pictures are shown. $\mathrm{n}=$ nucleus. Scale bar $=8 \mu \mathrm{M}$.

\section{Fig-2. AgNPs down-regulate Influenza-induced CCL-5 and IFN- $\beta$ production in human} lung epithelial cells. NCI-H292 (A, D, E, F), BEAS-2B (B, D), A549 (C, D) or primary lung epithelial cells $(\mathrm{G})$ were either incubated with Influenza virus (Flu) or with mock for 1-2h (Multiplicity of infection $(\mathrm{MOI})=0.25$ in $\mathrm{A}, \mathrm{B}, \mathrm{C}, \mathrm{D}$ and $\mathrm{MOI}=1 \mathrm{in} \mathrm{G})$. After washing, cells were treated with citrate (Cit-) coated silver nanoparticles (Ag NPs) $(2.5$ or $5 \mu \mathrm{g} / \mathrm{ml})$ or vehicle $(2 \mathrm{mM}$ citrate buffer $\mathrm{pH}$ 7.4) (in E and G AgNPs was $5 \mu \mathrm{g} / \mathrm{ml}$ ). Cytokines were measured in triplicates by 
commercial ELISAs 18h later. Same results were obtained with lipoic acid (La) Ag NPs (Fig-3).

In D) cytotoxicity (\% of lactate dehydrogenase (LDH) release) was measured by a commercial colorimetric assay. In F) viral replication was analysed by measuring the remaining pfu in the supernatant of infected cells by a plaque lyse assay (see Materials and Methods section) or by performing RT-qPCR (the relative expression of the viral protein M2 to HPRT was measured in total RNA). Mean \pm SEM of at least three independent experiments is shown (except for IL-8 production in $\mathrm{G}, \mathrm{n}=2) .{ }^{\#} \mathrm{p}<0.01,{ }^{\# \#} \mathrm{p}<0.001$ vs. Mock/vehicle, ${ }^{*} \mathrm{p}<0.05,{ }^{* *} \mathrm{p}<0.01,{ }^{* * *} \mathrm{p}<0.001$, ${ }^{* * * * *} \mathrm{p}<0.0001$ vs. Flu/vehicle, ANOVA test.

Fig-3. The AgNPs silver core, independently of coating, is essential for the down- regulation of Influenza-induced CCL-5. The indicated epithelial cell lines and primary cells were infected with Influenza virus (Flu) for $1-2 \mathrm{~h}$, cells were then washed and incubated with either $5 \mu \mathrm{g} / \mathrm{ml}$ of the indicated NPs, or with silver nitrate $(+\mathrm{Ag})(2.5 \mu \mathrm{g} / \mathrm{ml})$ or with a combination of silver nitrate and L-Cysteine (a scavenger for $\mathrm{Ag}$ free ions) $(25 \mu \mathrm{g} / \mathrm{ml})(+\mathrm{Ag}+\mathrm{Cys})$ for $18 \mathrm{~h}$. Concentration of CCL-5 in supernatants of infected cells were measured by a commercial ELISA and levels were compared against to Flu/vehicle cells $(100 \%)$. Mean \pm SEM of at least three independent experiments is shown (except for La-Ag- NPs and Cit-AuNPs in primary cells $\mathrm{n}=1$ performed in duplicates). ${ }^{* *} \mathrm{p}<0.01,{ }^{* * *} \mathrm{p}<0.001$ vs. Flu/vehicle, ANOVA test.

Fig-4. AgNPs specifically down-regulate RIG-I-dependent production of CCL5. NCI-H292 cells were incubated with $\mathrm{La}-\mathrm{Ag}$ NPs at the indicated concentrations for 5 hours and after washing cells were stimulated with $5^{\prime}$ triphosphate double stranded RNA (5'3p-dsRNA) $(1.2 \mu \mathrm{g} / \mathrm{ml})$ complexed to lipofectamine (A), polyinosinic-polycytidylic acid (poly IC) (10 $\mu \mathrm{g} / \mathrm{ml})$ 
(B) or (cyclic $\left.\left[\mathrm{G}\left(2^{\prime}, 5^{\prime}\right) \mathrm{pA}\left(3^{\prime}, 5^{\prime}\right) \mathrm{p}\right]\right)(\mathrm{cGAMP})(10 \mu \mathrm{g} / \mathrm{ml})(\mathrm{C}) .18 \mathrm{~h}$ after stimulation, CCL-5 and IL-6 were measured in cell supernatants by ELISA. Mean \pm SEM of at least three independent experiments is shown ${ }^{* *} \mathrm{p}<0.01,{ }^{* * *} \mathrm{p}<0.001 v s$. vehicle/stimulated cells, ANOVA test.

\section{Fig-5. AgNPs down-regulate IRF-7-mediated CCL-5 and IFN- $\beta$ production in Influenza-} infected cells. NCI-H292 cells expressing endogenous IRF-7 (IRF7-Wt), endogenous IRF3 (IRF3-Wt), as well as IRF-7 (IRF7-KO) or IRF-3 deficient cells (IRF3-KO) were infected with Influenza virus $(\mathrm{MOI}=0.5)(\mathrm{Flu})$ or treated with mock for $1 \mathrm{~h}$. After washing, cells were treated with La-AgNPs ( $5 \mu \mathrm{g} / \mathrm{ml})$ or vehicle for $18 \mathrm{~h}$. A) and C) show fold increase of CCL-5, IL-6, IL-8 and IFN- $\beta$ production in Influenza-infected cells from IRF7-Wt or IRF3-Wt cells (fold value=1) vs. IRF7-KO or IRF3-KO cells, respectively. Cytokines were measured by ELISA. B) Shows a representative experiment of $\mathrm{Wt}$ and $\mathrm{KO}$ Influenza-infected cells in the presence or absence of La-AgNPs $(5 \mu \mathrm{g} / \mathrm{ml})$. C) Same conditions as in B), shows the fold increase of cytokine production in Wt or IRF7-KO Influenza-infected cells (Flu) (fold value=1) treated or not with LaAgNPs. Mean \pm SEM of at least three independent experiments is shown. ${ }^{*} \mathrm{p}<0.05$, t-test.

\section{Fig-6. AgNPs increase lysosome-like vesicles numbers and modify lung epithelial cell} mitochondrial network. NCI-H292 cells were either treated with Cit-AgNPs ( $5 \mu \mathrm{g} / \mathrm{ml})$ (AgNPs) or with vehicle (CTRL) for $5 \mathrm{~h}$ and then transfected with 5 '3p-dsRNA $(1.2 \mu \mathrm{g} / \mathrm{ml})$ (a ligand for RIG-I) complexed with lipofectamine or treated with lipofectamine alone (CTRL). 18h later, living cells were labelled with LysoTracker ${ }^{\circledR}$ Green DND-26 (20nM) and MitoTracker ${ }^{\circledR}$ Red CMXRos (250nM) for $30 \mathrm{~min}$ at $37^{\circ} \mathrm{C}$. After washing, living cells were imaged with a Richardson dark-field and fluorescence microscope. The same field of view was imaged with 
dark-field illumination as well as with green and red fluorescence filters. Image overlay was created in Image $\mathrm{J}$ programme. $\mathrm{n}=$ nucleus. White arrows and circled regions indicate aggregates of AgNPs/mitochondria/acidic vesicles. Scale bar $=8 \mu \mathrm{M}$.

Fig-7. AgNPs block the autophagic flux and enhance the cytosolic and mitochondrial partition of IRF-7, preventing further nuclear migration. A) NCI-H292 cells were incubated with La-AgNPs $(5 \mu \mathrm{g} / \mathrm{ml})$ for $18 \mathrm{~h}$. After washing, cells were included in epoxy resin to perform ultrathin sections that were then analysed by TEM without contrast agent (black arrows indicate

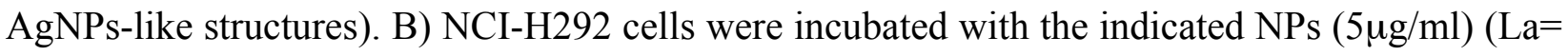
lipoic acid coated; Cit=citrate coated, $\mathrm{Au}=$ gold) for $18 \mathrm{~h}$ and after washing Western blot of cell lysates was performed with specific antibodies against LC3, SQSTM1/p62 and GAPDH (after sequential re-probing of the same membrane). C) NCI-H292 cells were infected with Influenza virus $(\mathrm{MOI}=0.25)(\mathrm{Flu})$ and then treated with La-AgNPs $(5 \mu \mathrm{g} / \mathrm{ml})$ or with Influenza virus alone. Western blots of cell lysates were performed as described in B). D) NCI-H292 cells grown onto glass coverslips were infected with Influenza virus $(\mathrm{MOI}=0.25)$ and then treated with La-AgNPs $(5 \mu \mathrm{g} / \mathrm{ml})$ or infected with Influenza virus alone. Fixed cells were stained with anti-LC3 A555coupled antibodies (red) and anti-Tom20 A488-coupled antibodies (green) and visualized with confocal microscopy. Nuclei were stained with DAPI (Blue). Images taken for each filter and under bright field were merged with Image J programme. Scale bar $=10 \mu \mathrm{m}$. White arrows indicate AgNPs-like structures observed under bright field. E) Mitochondrial, cytosolic and nuclear fractions were isolated from either untreated NCI-H292 cells (CTRL), cells infected with Influenza virus alone (MOI 0.25) (Flu), treated with La-AgNPs alone (AgNP), or infected and then treated with the same concentration of La-AgNPs (Flu+AgNP). Western blot was performed 
from cellular extracts to detect the expression of IRF-7 in mitochondrial, cytosolic and nuclear fractions $(5 \mu \mathrm{g}, 10 \mu \mathrm{g}$ and $20 \mu \mathrm{g}$, respectively). Enrichment of each fraction in protein extracts was monitored using COX4, $\beta$-tubulin ( $\beta$-tub), Lamin A/C (Lam) expression, respectively. Right panels show the relative quantification of IRF-7 in Influenza (arbitrary units=1) and Influenza + AgNPs cells in the different fractions ( $\mathrm{n}=3$ independent extracts). F) Cells treated under the same conditions described in D) were fixed and stained with rabbit anti-Tom20 antibodies and mouse anti-IRF-7 antibodies. Anti-rabbit coupled to A555 (Red) and anti-mouse coupled to A488 (green) secondary antibodies were then added to visualize mitochondria (Tom20) and IRF-7 localisation by confocal microscopy. Nuclei were stained with DAPI (Blue). A representative picture of Influenza and Influenza + AgNPs conditions is shown. Scale bar $=10$ $\mu \mathrm{m}$.

Fig-8. AgNPs down-regulate CCL-5 and IFN- $\beta$ in Influenza-infected cells through the alternative autophagy. A) Left panel: BEAS-2B cells were either infected with Influenza virus $(\mathrm{MOI}=1)(\mathrm{Flu})$ and then incubated with La-AgNPs $(5 \mu \mathrm{g} / \mathrm{ml})$ or with Influenza virus alone. Right panel: cells (WT or ATG5 deficient (ATG-5 KO)) (two different clones are shown) were treated with chloroquine (CQ) $(25 \mu \mathrm{M})$. After 18h, cells were lysed in RIPA buffer and Western blots were performed with the indicated antibodies. B) BEAS-2B cells grown onto glass coverslips were infected with Influenza virus $(\mathrm{MOI}=1)(\mathrm{Flu})$ and then treated with $\mathrm{La}-\mathrm{AgNPs}(5 \mu \mathrm{g} / \mathrm{ml})$. Fixed cells were stained with rabbit anti-Rab9 antibody and mouse anti-Lamp2 antibody followed by incubation with the corresponding secondary antibodies (anti-rabbit A555-coupled (red) and anti-mouse A488-coupled (green)). Samples were analysed in a confocal microscope. Nuclei were stained with DAPI (Blue). Images taken for each filter and under bright field were 
merged with the Image J programme. Scale bar $=10 \mu \mathrm{m}$. White arrows indicate AgNPs-like structures observed under bright field. C) WT BEAS-2B cells (ATG5-WT) or ATG5 deficient (ATG5-KO) were either infected with Influenza virus $(\mathrm{MOI}=1)$ (Flu) or mock, and then treated or not with La-AgNPs $(5 \mu \mathrm{g} / \mathrm{ml})$ in the presence of $2.5 \mathrm{mM}$ 3-MA (3-Methyladenine). After 18h, supernatants were collected and cytokines analysed by sandwich ELISA. Percentage reduction of cytokine levels relative to the corresponding "Flu" levels is indicated. D) WT BEAS-2B cells or ATG5 deficient (ATG5-KO) were infected with Influenza virus and treated or not with LaAgNPs as described in C), in the presence of the indicated concentrations of 3-MA (0-5mM). Fold increase in Influenza infected cells was calculated for each independent experiment and report to cytokine concentration in the supernatants of Influenza-infected cells without AgNPs or 3-MA (fold value $=1$ ). Mean \pm SEM of at least three independent experiments is shown. ${ }^{*} \mathrm{p}<0.05$, ${ }^{* *} \mathrm{p}<0.01,{ }^{* * *} \mathrm{p}<0.001 \mathrm{Flu} v$ s. Flu/AgNPs for each concentration of 3-MA, t-test.

\section{Supporting Information.}

File: "Supplementary Figures and Tables.pdf”. Legends and Figures S1 to S10 and Table 1S File: "Video-S1.avi". Association of Cit-AgNPs with intracellular vesicles in human cells lines File: "Video-S2.avi". Association of Cit-AgNPs with lamellar bodies in rat alveolar type II epithelial cells 


\section{REFERENCES}

1. Lara, H. H.; Garza-Trevino, E. N.; Ixtepan-Turrent, L.; Singh, D. K. Silver Nanoparticles Are Broad-Spectrum Bactericidal and Virucidal Compounds. J Nanobiotechnology 2011, 9, 1. 2. Xiang, D.; Zheng, Y.; Duan, W.; Li, X.; Yin, J.; Shigdar, S.; O'Connor, M. L.; Marappan, M.; Zhao, X.; Miao, Y.; Xiang, B.; Zheng, C. Inhibition of a/Human/Hubei/3/2005 (H3n2) Influenza Virus Infection by Silver Nanoparticles in Vitro and in Vivo. Int J Nanomedicine 2013, 8, 4103-13.

3. Maillard, J. Y.; Hartemann, P. Silver as an Antimicrobial: Facts and Gaps in Knowledge. Crit Rev Microbiol 2013, 39, 373-83.

4. De Matteis, V.; Malvindi, M. A.; Galeone, A.; Brunetti, V.; De Luca, E.; Kote, S.; Kshirsagar, P.; Sabella, S.; Bardi, G.; Pompa, P. P. Negligible Particle-Specific Toxicity Mechanism of Silver Nanoparticles: The Role of Ag+ Ion Release in the Cytosol. Nanomedicine 2015, 11, 731-9.

5. Sabella, S.; Carney, R. P.; Brunetti, V.; Malvindi, M. A.; Al-Juffali, N.; Vecchio, G.; Janes, S. M.; Bakr, O. M.; Cingolani, R.; Stellacci, F.; Pompa, P. P. A General Mechanism for Intracellular Toxicity of Metal-Containing Nanoparticles. Nanoscale 2014, 6, 7052-61.

6. Delaval, M.; Boland, S.; Solhonne, B.; Nicola, M. A.; Mornet, S.; Baeza-Squiban, A.; Sallenave, J. M.; Garcia-Verdugo, I. Acute Exposure to Silica Nanoparticles Enhances Mortality and Increases Lung Permeability in a Mouse Model of Pseudomonas Aeruginosa Pneumonia. Part Fibre Toxicol 2015, 12, 1.

7. Kim, J. S.; Adamcakova-Dodd, A.; O'Shaughnessy, P. T.; Grassian, V. H.; Thorne, P. S. Effects of Copper Nanoparticle Exposure on Host Defense in a Murine Pulmonary Infection Model. Part Fibre Toxicol 2011, 8, 29.

8. Carlson, C.; Hussain, S. M.; Schrand, A. M.; Braydich-Stolle, L. K.; Hess, K. L.; Jones, R. L.; Schlager, J. J. Unique Cellular Interaction of Silver Nanoparticles: Size-Dependent Generation of Reactive Oxygen Species. J Phys Chem B 2008, 112, 13608-19.

9. Klippstein, R.; Fernandez-Montesinos, R.; Castillo, P. M.; Zaderenko, A. P.; Pozo, D., Silver Nanoparticles Interactions with the Immune System: Implications for Health and Disease. In Silver Nanoparticles, Pozo Perez, D., Ed. InTech: 2010; pp 319-324. 
10. Samberg, M. E.; Oldenburg, S. J.; Monteiro-Riviere, N. A. Evaluation of Silver Nanoparticle Toxicity in Skin in Vivo and Keratinocytes in Vitro. Environ Health Perspect 2010, 118, 407-13.

11. AshaRani, P. V.; Low Kah Mun, G.; Hande, M. P.; Valiyaveettil, S. Cytotoxicity and Genotoxicity of Silver Nanoparticles in Human Cells. ACS Nano 2009, 3, 279-90.

12. Costa, C. S.; Ronconi, J. V.; Daufenbach, J. F.; Goncalves, C. L.; Rezin, G. T.; Streck, E. L.;

Paula, M. M. In Vitro Effects of Silver Nanoparticles on the Mitochondrial Respiratory Chain. Mol Cell Biochem 2010, 342, 51-6.

13. Mao, B. H.; Tsai, J. C.; Chen, C. W.; Yan, S. J.; Wang, Y. J. Mechanisms of Silver Nanoparticle-Induced Toxicity and Important Role of Autophagy. Nanotoxicology 2016, 10, 1021-40.

14. Mizushima, N.; Noda, T.; Yoshimori, T.; Tanaka, Y.; Ishii, T.; George, M. D.; Klionsky, D. J.; Ohsumi, M.; Ohsumi, Y. A Protein Conjugation System Essential for Autophagy. Nature 1998, 395, 395-8.

15. Arakawa, S.; Honda, S.; Yamaguchi, H.; Shimizu, S. Molecular Mechanisms and Physiological Roles of Atg5/Atg7-Independent Alternative Autophagy. Proc Jpn Acad Ser B Phys Biol Sci 2017, 93, 378-385.

16. Nishida, Y.; Arakawa, S.; Fujitani, K.; Yamaguchi, H.; Mizuta, T.; Kanaseki, T.; Komatsu, M.; Otsu, K.; Tsujimoto, Y.; Shimizu, S. Discovery of Atg5/Atg7-Independent Alternative Macroautophagy. Nature 2009, 461, 654-8.

17. Jounai, N.; Takeshita, F.; Kobiyama, K.; Sawano, A.; Miyawaki, A.; Xin, K. Q.; Ishii, K. J.; Kawai, T.; Akira, S.; Suzuki, K.; Okuda, K. The Atg5 Atg12 Conjugate Associates with Innate Antiviral Immune Responses. Proc Natl Acad Sci U S A 2007, 104, 14050-5.

18. Meylan, E.; Tschopp, J.; Karin, M. Intracellular Pattern Recognition Receptors in the Host Response. Nature 2006, 442, 39-44.

19. Hou, F.; Sun, L.; Zheng, H.; Skaug, B.; Jiang, Q. X.; Chen, Z. J. Mavs Forms Functional Prion-Like Aggregates to Activate and Propagate Antiviral Innate Immune Response. Cell 2011, 146, 448-61.

20. Balamayooran, G.; Batra, S.; Fessler, M. B.; Happel, K. I.; Jeyaseelan, S. Mechanisms of Neutrophil Accumulation in the Lungs against Bacteria. Am J Respir Cell Mol Biol 2010, 43, 5-16. 
21. Herzog, F.; Clift, M. J.; Piccapietra, F.; Behra, R.; Schmid, O.; Petri-Fink, A.; RothenRutishauser, B. Exposure of Silver-Nanoparticles and Silver-Ions to Lung Cells in Vitro at the Air-Liquid Interface. Part Fibre Toxicol 2013, 10, 11.

22. Martinez-Gutierrez, F.; Thi, E. P.; Silverman, J. M.; de Oliveira, C. C.; Svensson, S. L.; Vanden Hoek, A.; Sanchez, E. M.; Reiner, N. E.; Gaynor, E. C.; Pryzdial, E. L.; Conway, E. M.; Orrantia, E.; Ruiz, F.; Av-Gay, Y.; Bach, H. Antibacterial Activity, Inflammatory Response, Coagulation and Cytotoxicity Effects of Silver Nanoparticles. Nanomedicine 2012, 8, 328-36. 23. Barbier, D.; Garcia-Verdugo, I.; Pothlichet, J.; Khazen, R.; Descamps, D.; Rousseau, K.; Thornton, D.; Si-Tahar, M.; Touqui, L.; Chignard, M.; Sallenave, J. M. Influenza a Induces the Major Secreted Airway Mucin Muc5ac in a Protease-Egfr-Extracellular Regulated KinaseSp1-Dependent Pathway. Am J Respir Cell Mol Biol 2012, 47, 149-57.

24. Matsukura, S.; Kokubu, F.; Noda, H.; Tokunaga, H.; Adachi, M. Expression of Il-6, Il-8, and Rantes on Human Bronchial Epithelial Cells, Nci-H292, Induced by Influenza Virus A. J Allergy Clin Immunol 1996, 98, 1080-7.

25. Sugimoto, N.; Mitoma, H.; Kim, T.; Hanabuchi, S.; Liu, Y. J. Helicase Proteins Dhx29 and Rig-I Cosense Cytosolic Nucleic Acids in the Human Airway System. Proc Natl Acad Sci U $S$ A 2014, 111, 7747-52.

26. Genin, P.; Algarte, M.; Roof, P.; Lin, R.; Hiscott, J. Regulation of Rantes Chemokine Gene Expression Requires Cooperativity between Nf-Kappa B and Ifn-Regulatory Factor Transcription Factors. J Immunol 2000, 164, 5352-61.

27. Ozato, K.; Tailor, P.; Kubota, T. The Interferon Regulatory Factor Family in Host Defense: Mechanism of Action. J Biol Chem 2007, 282, 20065-9.

28. Fitzgerald, K. A.; McWhirter, S. M.; Faia, K. L.; Rowe, D. C.; Latz, E.; Golenbock, D. T.; Coyle, A. J.; Liao, S. M.; Maniatis, T. Ikkepsilon and Tbk1 Are Essential Components of the Irf3 Signaling Pathway. Nat Immunol 2003, 4, 491-6.

29. Guillot, L.; Le Goffic, R.; Bloch, S.; Escriou, N.; Akira, S.; Chignard, M.; Si-Tahar, M. Involvement of Toll-Like Receptor 3 in the Immune Response of Lung Epithelial Cells to Double-Stranded Rna and Influenza a Virus. J Biol Chem 2005, 280, 5571-80.

30. Liu, S.; Cai, X.; Wu, J.; Cong, Q.; Chen, X.; Li, T.; Du, F.; Ren, J.; Wu, Y. T.; Grishin, N. V.; Chen, Z. J. Phosphorylation of Innate Immune Adaptor Proteins Mavs, Sting, and Trif Induces Irf3 Activation. Science 2015, 347, aaa2630. 
31. Ning, S.; Pagano, J. S.; Barber, G. N. Irf7: Activation, Regulation, Modification and Function. Genes Immun 2011, 12, 399-414.

32. Melchjorsen, J.; Sorensen, L. N.; Paludan, S. R. Expression and Function of Chemokines During Viral Infections: From Molecular Mechanisms to in Vivo Function. $J$ Leukoc Biol 2003, 74, 331-43.

33. Castanier, C.; Garcin, D.; Vazquez, A.; Arnoult, D. Mitochondrial Dynamics Regulate the Rig-I-Like Receptor Antiviral Pathway. EMBO Rep 2010, 11, 133-8.

34. Han, J. W.; Gurunathan, S.; Jeong, J. K.; Choi, Y. J.; Kwon, D. N.; Park, J. K.; Kim, J. H. Oxidative Stress Mediated Cytotoxicity of Biologically Synthesized Silver Nanoparticles in Human Lung Epithelial Adenocarcinoma Cell Line. Nanoscale Res Lett 2014, 9, 459.

35. Haberl, N.; Hirn, S.; Wenk, A.; Diendorf, J.; Epple, M.; Johnston, B. D.; Krombach, F.; Kreyling, W. G.; Schleh, C. Cytotoxic and Proinflammatory Effects of Pvp-Coated Silver Nanoparticles after Intratracheal Instillation in Rats. Beilstein J Nanotechnol 2013, 4, 93340.

36. Ahlberg, S.; Antonopulos, A.; Diendorf, J.; Dringen, R.; Epple, M.; Flock, R.; Goedecke, W.; Graf, C.; Haberl, N.; Helmlinger, J.; Herzog, F.; Heuer, F.; Hirn, S.; Johannes, C.; Kittler, S.; Koller, M.; Korn, K.; Kreyling, W. G.; Krombach, F.; Lademann, J.; Loza, K.; Luther, E. M.; Malissek, M.; Meinke, M. C.; Nordmeyer, D.; Pailliart, A.; Raabe, J.; Rancan, F.; RothenRutishauser, B.; Ruhl, E.; Schleh, C.; Seibel, A.; Sengstock, C.; Treuel, L.; Vogt, A.; Weber, K.; Zellner, R. Pvp-Coated, Negatively Charged Silver Nanoparticles: A Multi-Center Study of Their Physicochemical Characteristics, Cell Culture and in Vivo Experiments. Beilstein J Nanotechnol 2014, 5, 1944-65.

37. Kim, H. J.; Lee, S.; Jung, J. U. When Autophagy Meets Viruses: A Double-Edged Sword with Functions in Defense and Offense. Semin Immunopathol 2010, 32, 323-41.

38. Di Trani, L.; Savarino, A.; Campitelli, L.; Norelli, S.; Puzelli, S.; D'Ostilio, D.; Vignolo, E.; Donatelli, I.; Cassone, A. Different Ph Requirements Are Associated with Divergent Inhibitory Effects of Chloroquine on Human and Avian Influenza a Viruses. Virol J 2007, 4, 39.

39. Yeganeh, B.; Ghavami, S.; Kroeker, A. L.; Mahood, T. H.; Stelmack, G. L.; Klonisch, T.; Coombs, K. M.; Halayko, A. J. Suppression of Influenza a Virus Replication in Human Lung 
Epithelial Cells by Noncytotoxic Concentrations Bafilomycin A1. Am J Physiol Lung Cell Mol Physiol 2015, 308, L270-86.

40. Sun, Y.; Li, C.; Shu, Y.; Ju, X.; Zou, Z.; Wang, H.; Rao, S.; Guo, F.; Liu, H.; Nan, W.; Zhao, Y.; Yan, Y.; Tang, J.; Zhao, C.; Yang, P.; Liu, K.; Wang, S.; Lu, H.; Li, X.; Tan, L.; Gao, R.; Song, J.; Gao, X.; Tian, X.; Qin, Y.; Xu, K. F.; Li, D.; Jin, N.; Jiang, C. Inhibition of Autophagy Ameliorates Acute Lung Injury Caused by Avian Influenza a H5n1 Infection. Sci Signal 2012, 5, ra16.

41. Liu, Q.; Zhou, Y. H.; Yang, Z. Q. The Cytokine Storm of Severe Influenza and Development of Immunomodulatory Therapy. Cell Mol Immunol 2016, 13, 3-10.

42. Peiris, J. S.; Hui, K. P.; Yen, H. L. Host Response to Influenza Virus: Protection Versus Immunopathology. Curr Opin Immunol 2010, 22, 475-81.

43. Guilliams, M.; Lambrecht, B. N.; Hammad, H. Division of Labor between Lung Dendritic Cells and Macrophages in the Defense against Pulmonary Infections. Mucosal Immunol 2013, 6, 464-73.

44. Xu, Y.; Wang, L.; Bai, R.; Zhang, T.; Chen, C. Silver Nanoparticles Impede Phorbol Myristate Acetate-Induced Monocyte-Macrophage Differentiation and Autophagy. Nanoscale 2015, 7, 16100-9.

45. Jia, L.; Xie, J.; Zhao, J.; Cao, D.; Liang, Y.; Hou, X.; Wang, L.; Li, Z. Mechanisms of Severe Mortality-Associated Bacterial Co-Infections Following Influenza Virus Infection. Front Cell Infect Microbiol 2017, 7, 338.

46. Benyahia, C.; Ozen, G.; Orie, N.; Ledwozyw, A.; Louedec, L.; Li, F.; Senbel, A. M.; Silverstein, A.; Danel, C.; Longrois, D.; Clapp, L. H.; Norel, X.; Topal, G. Ex Vivo Relaxations of Pulmonary Arteries Induced by Prostacyclin Mimetics Are Highly Dependent of the Precontractile Agents. Prostaglandins Other Lipid Mediat 2015, 121, 46-52.

47. Mao, P.; Wu, S.; Li, J.; Fu, W.; He, W.; Liu, X.; Slutsky, A. S.; Zhang, H.; Li, Y. Human Alveolar Epithelial Type Ii Cells in Primary Culture. Physiol Rep 2015, 3, e12288.

48. Raoust, E.; Balloy, V.; Garcia-Verdugo, I.; Touqui, L.; Ramphal, R.; Chignard, M. Pseudomonas Aeruginosa Lps or Flagellin Are Sufficient to Activate Tlr-Dependent Signaling in Murine Alveolar Macrophages and Airway Epithelial Cells. PLoS One 2009, 4, e7259. 
49. Miklavc, P.; Wittekindt, O. H.; Felder, E.; Dietl, P. Ca2+-Dependent Actin Coating of Lamellar Bodies after Exocytotic Fusion: A Prerequisite for Content Release or Kiss-andRun. Ann N Y Acad Sci 2009, 1152, 43-52.

50. Garcia-Verdugo, I.; Ravasio, A.; de Paco, E. G.; Synguelakis, M.; Ivanova, N.; Kanellopoulos, J.; Haller, T. Long-Term Exposure to Lps Enhances the Rate of Stimulated Exocytosis and Surfactant Secretion in Alveolar Type Ii Cells and Upregulates P2y2 Receptor Expression. Am J Physiol Lung Cell Mol Physiol 2008, 295, L708-17.

51. Edelstein, A. D.; Tsuchida, M. A.; Amodaj, N.; Pinkard, H.; Vale, R. D.; Stuurman, N. Advanced Methods of Microscope Control Using Mumanager Software. J Biol Methods 2014, 1, e10. 


\begin{tabular}{cccccc} 
Core & Coating & $\begin{array}{c}\text { Diameter } \\
(\mathrm{nm})\end{array}$ & $\begin{array}{c}\text { Hydrodinamic Diameter } \\
(\mathrm{nm})\end{array}$ & $\begin{array}{c}\text { Zeta Potential } \\
(\mathrm{mV})\end{array}$ & $\begin{array}{c}\text { Endotoxin } \\
(\mathrm{EU} / \mathrm{m})\end{array}$ \\
\hline $\mathrm{Ag}$ & Citrate & $9.6 \pm 2$ & 13.3 & -39.4 & $<5$ \\
\hline $\mathrm{Ag}$ & Lipoic acid & $9.4 \pm 1.8$ & 17.1 & -51.8 & $<5$ \\
\hline $\mathrm{Au}$ & Citrate & $11.3 \pm 0.9$ & 12.4 & -23.7 & $<5$ \\
\hline $\mathrm{Au}$ & Lipoic acid & $7.5 \pm 0.8$ & n.r & n.r & $<2.5$ \\
\hline
\end{tabular}

Table-1 
NCl-H292

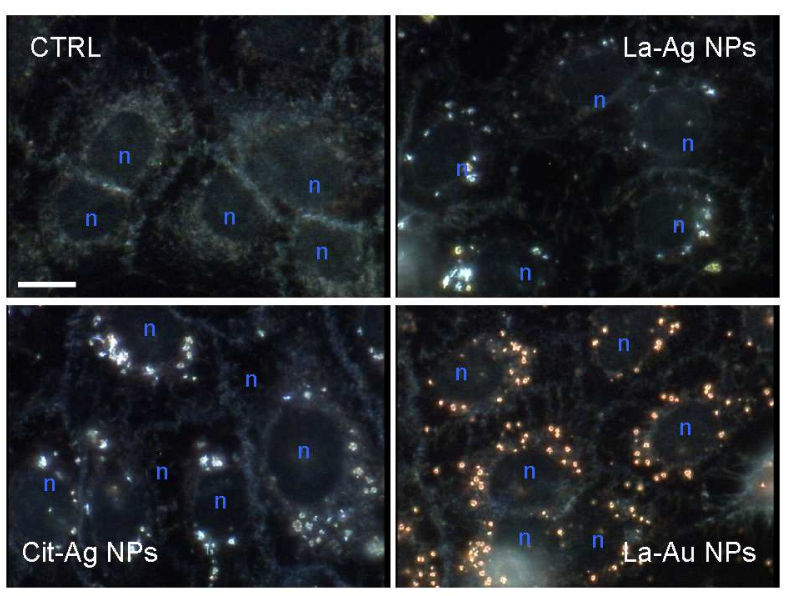

BEAS-2B
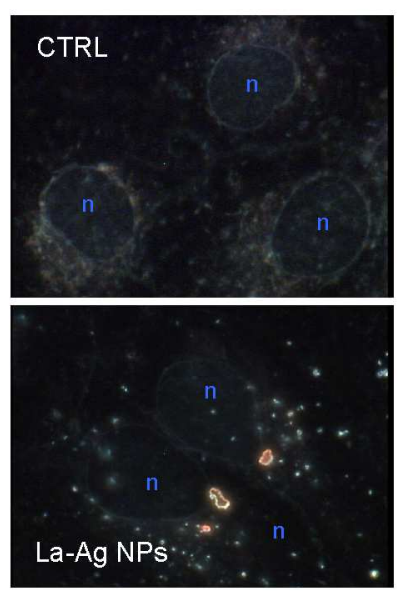

A549

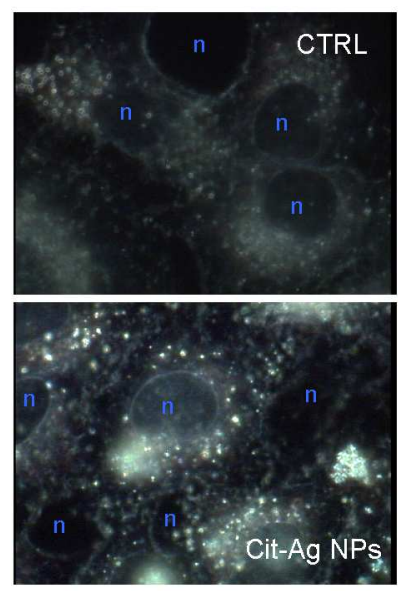

Fig-1 
A) $\mathrm{NCl}-\mathrm{H} 292$
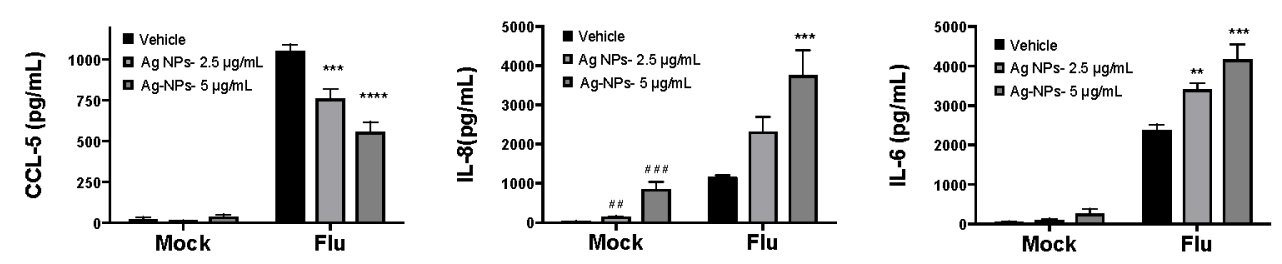

B) BEAS-2B
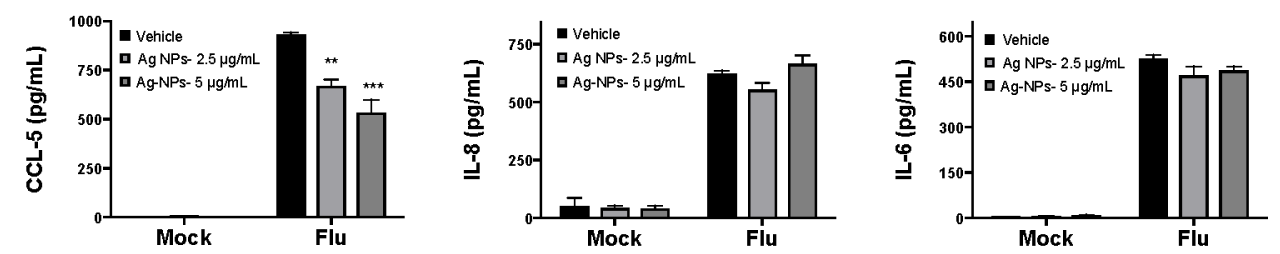

C) $\mathbf{A 5 4 9}$
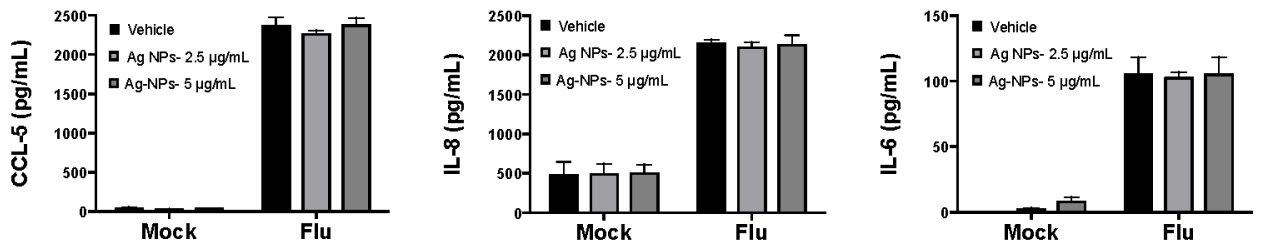

D)
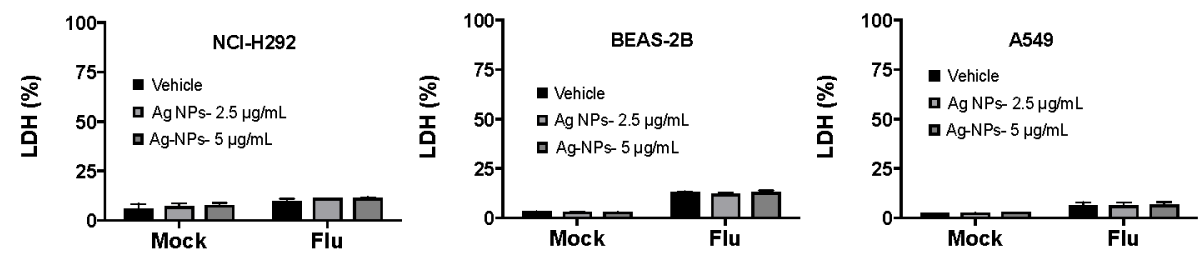

E)

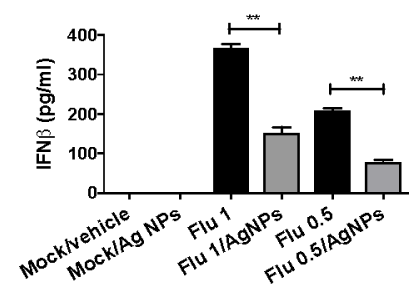

F)

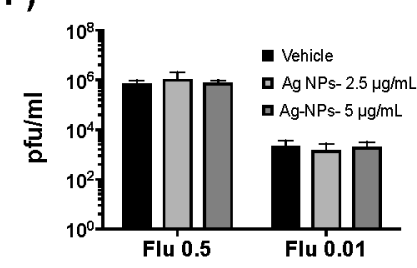

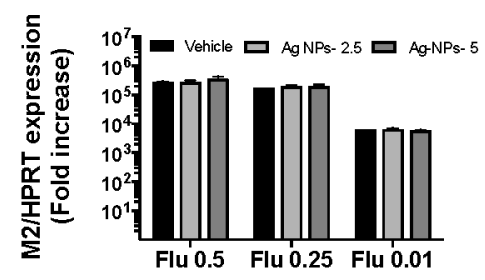

G)
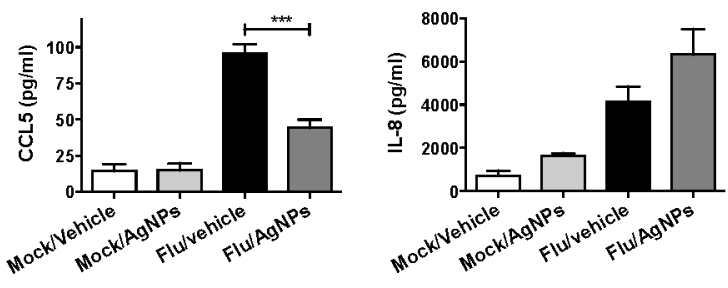

Fig-2 
$\mathrm{NCl}-\mathrm{H} 292$

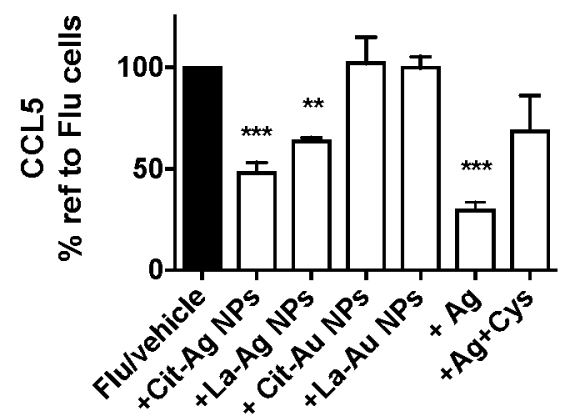

Primary cells

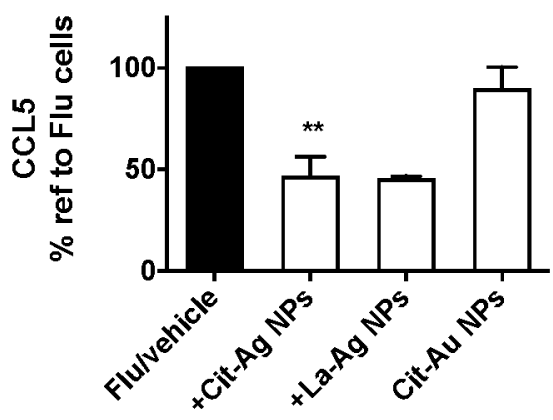

BEAS-2B

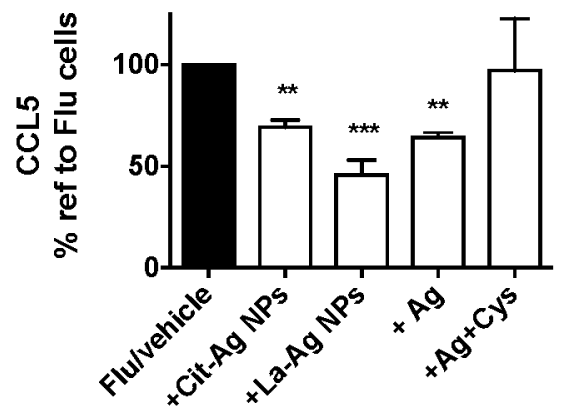

A549

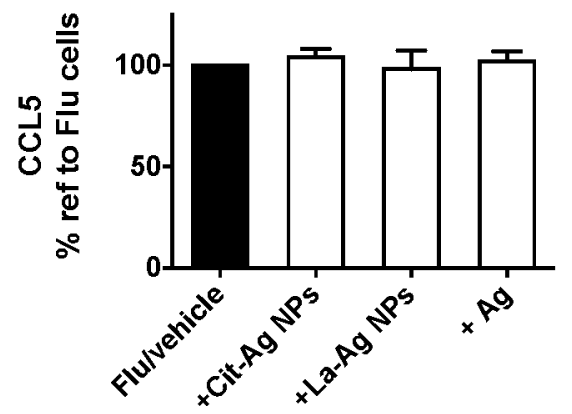

Fig-3 
A)

RIG-I ligand
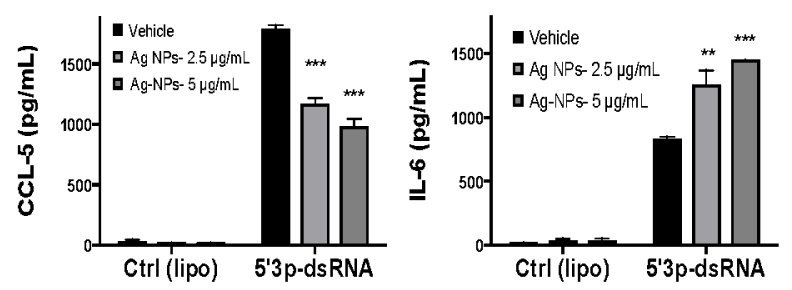

C)

\section{STING ligand}
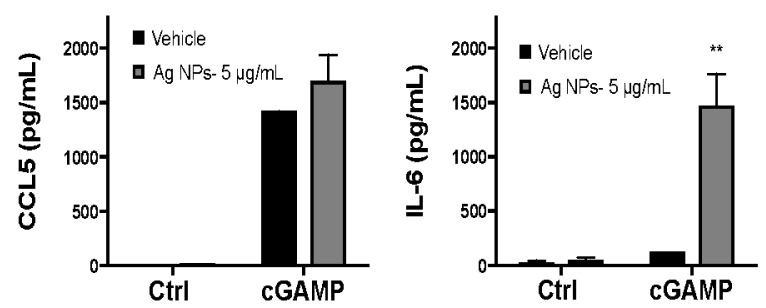

B)

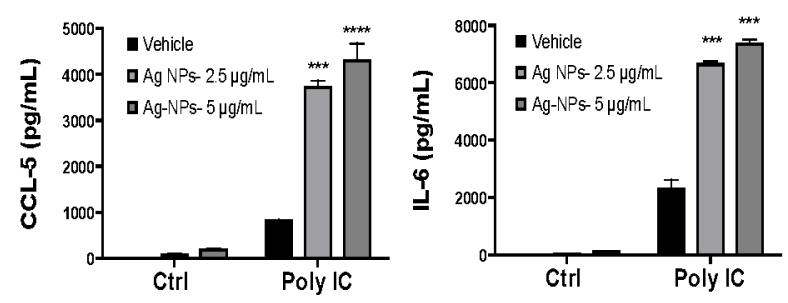

Fig-4 
A)
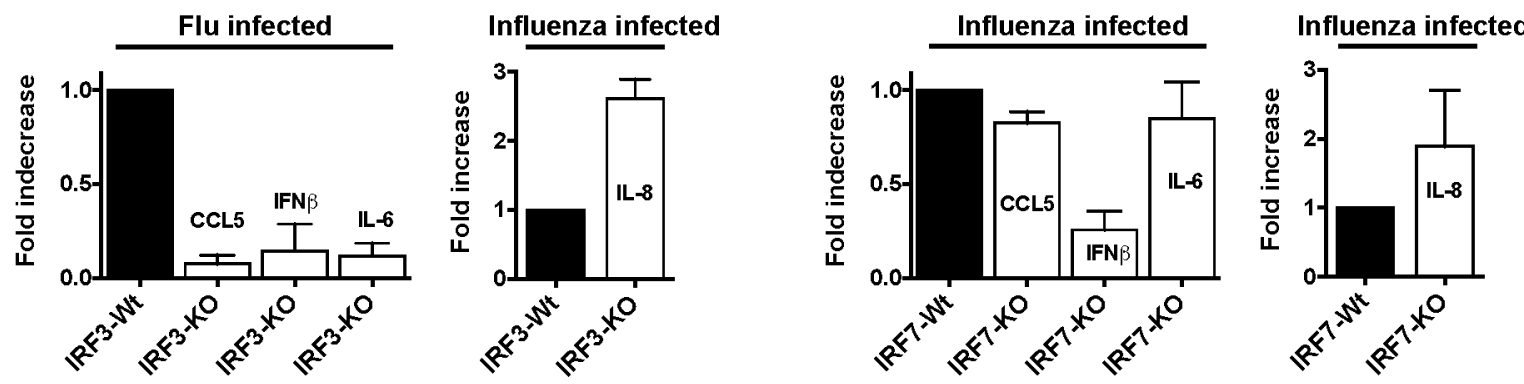

B)

C)
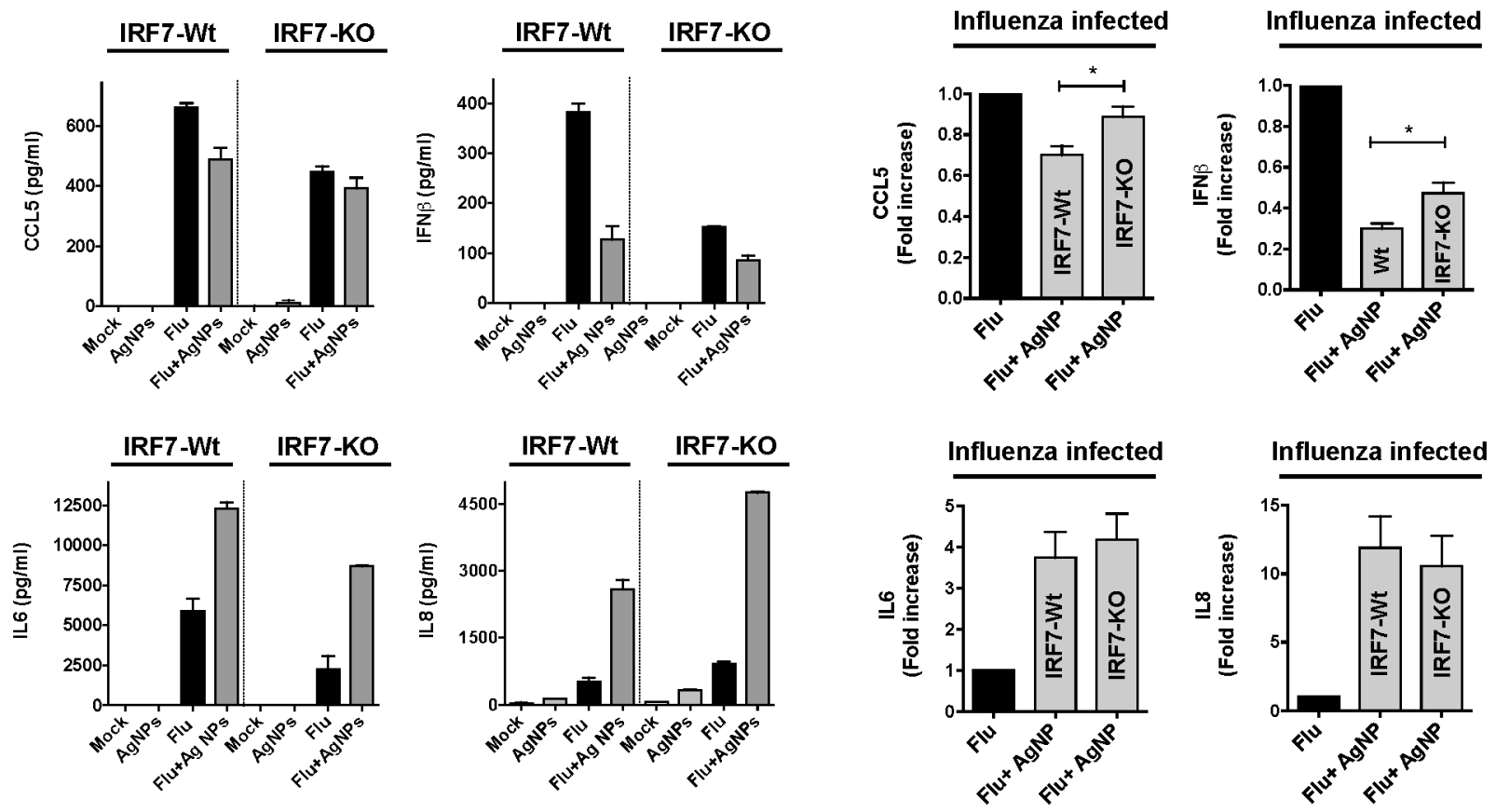

Fig-5 


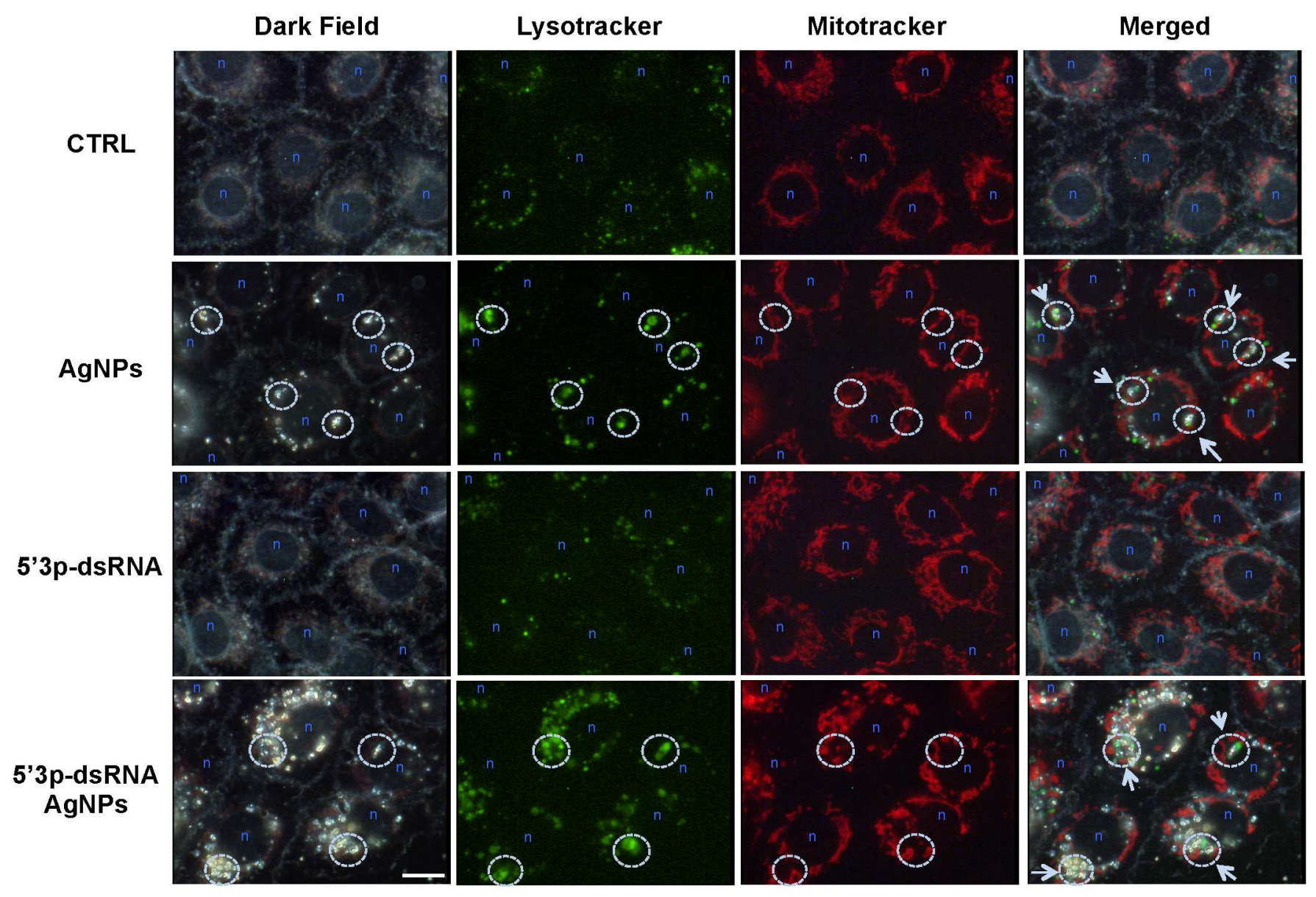

Fig-6 
A)

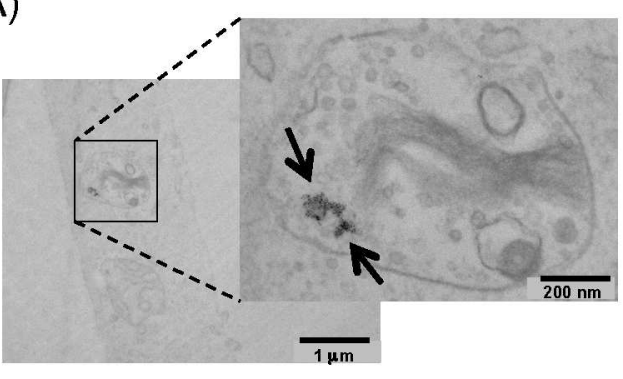

B)

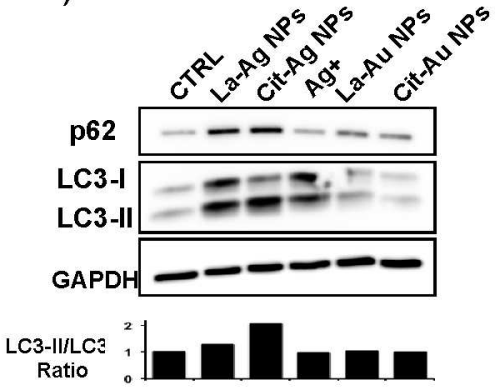

C)

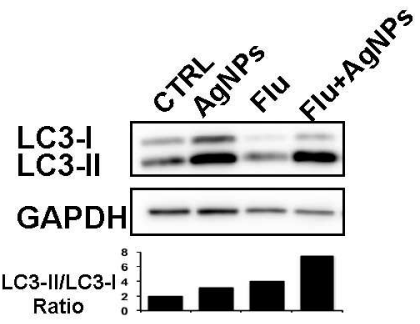

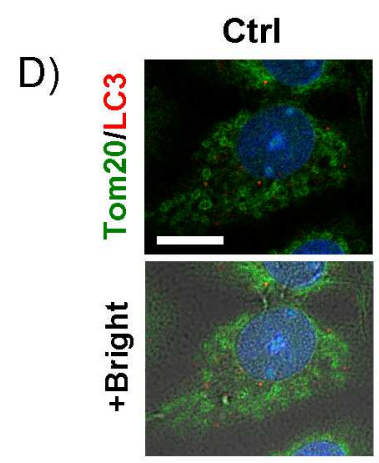

AgNPs

FI

Flu+ AgNPs
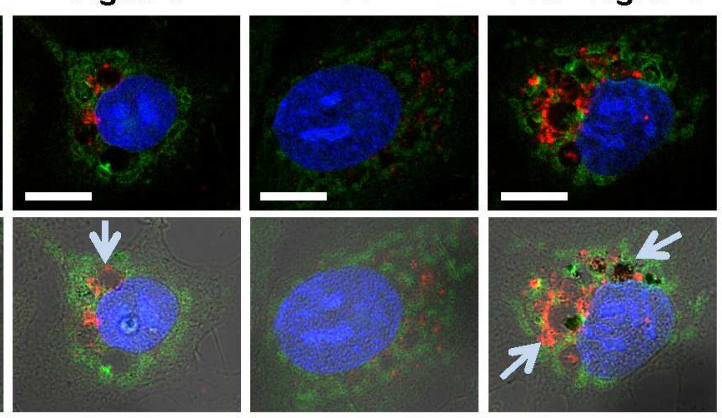

E)
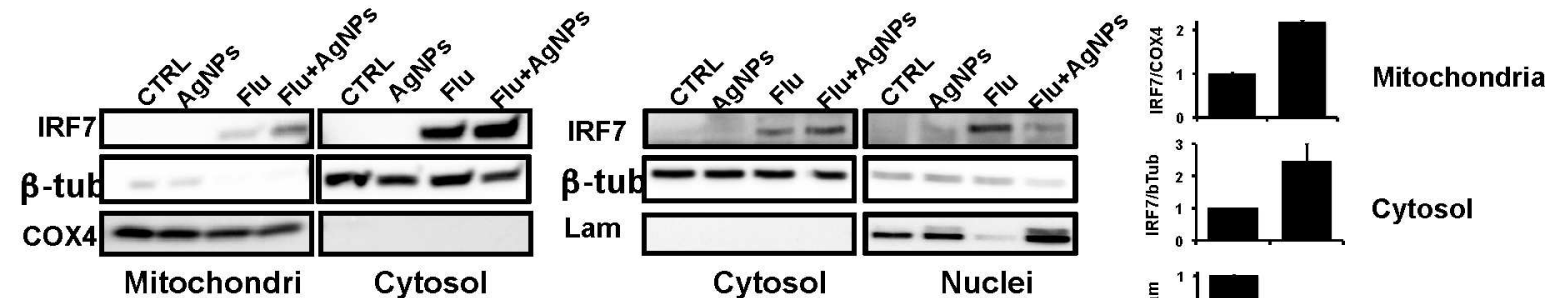

F)
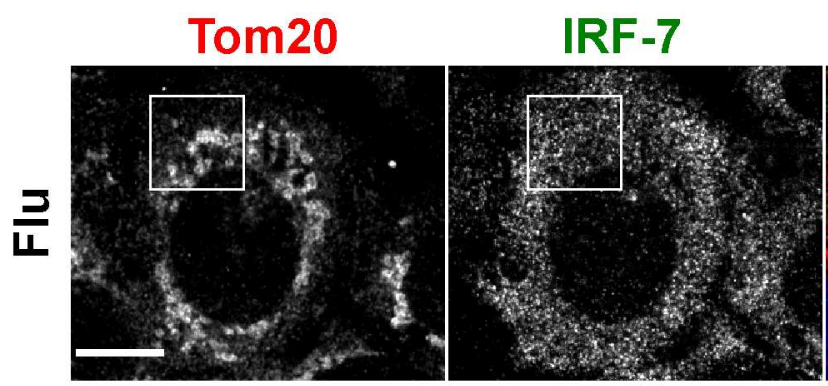

Merge/Dapi
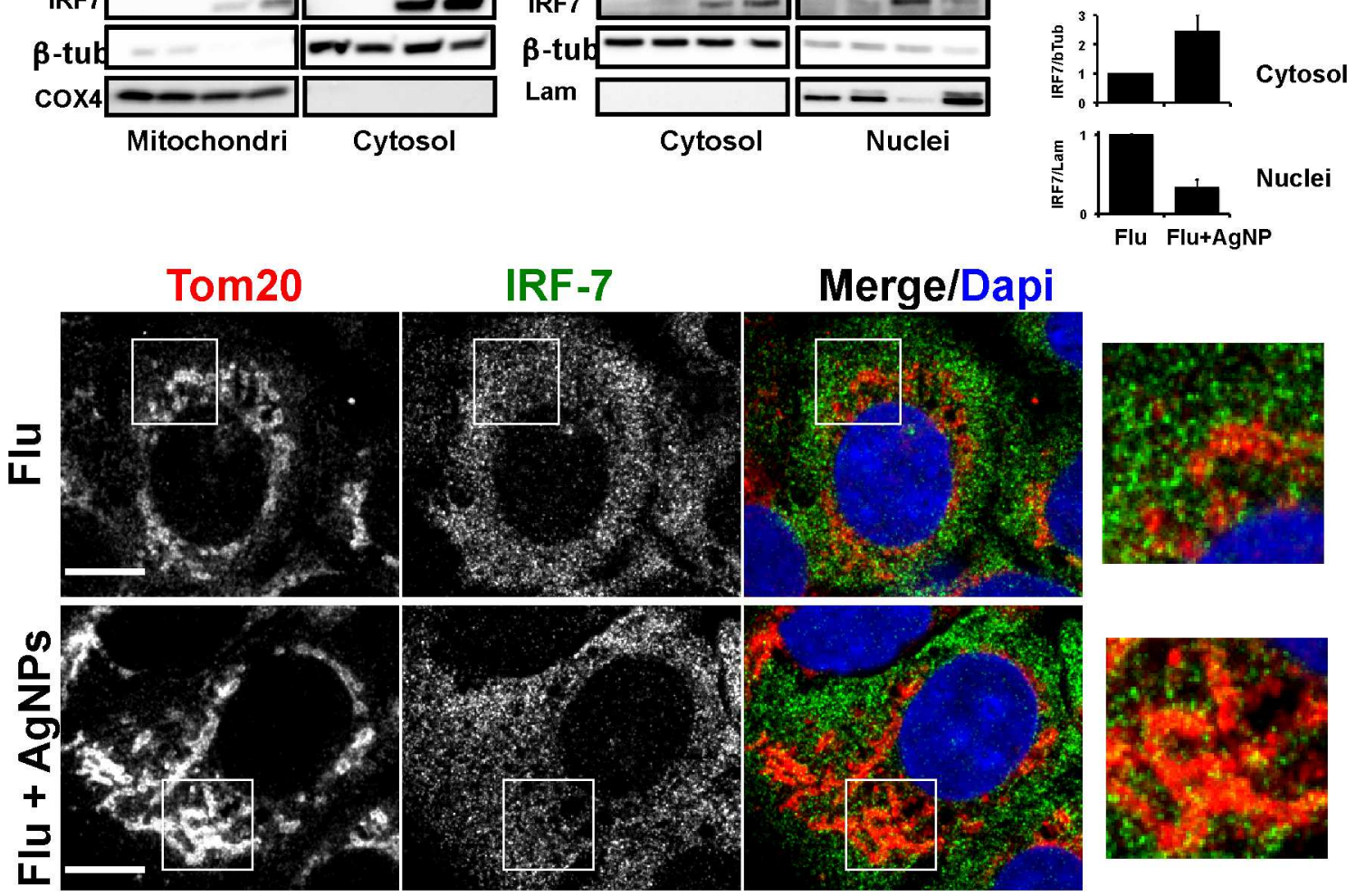

Fig-7
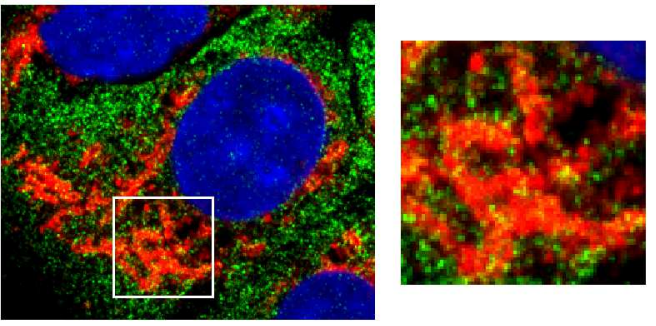
A)

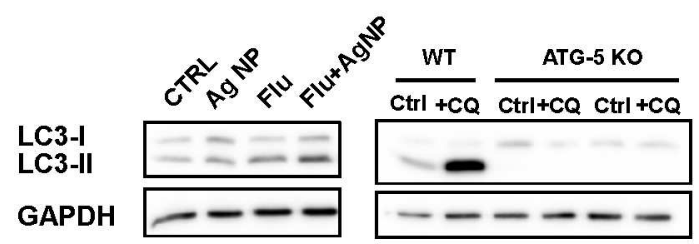

C)
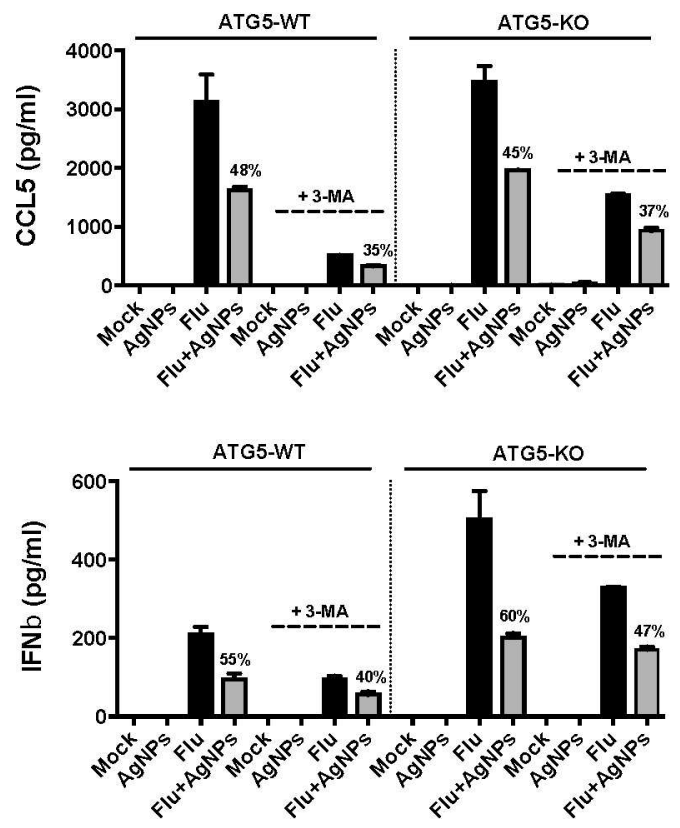

D)

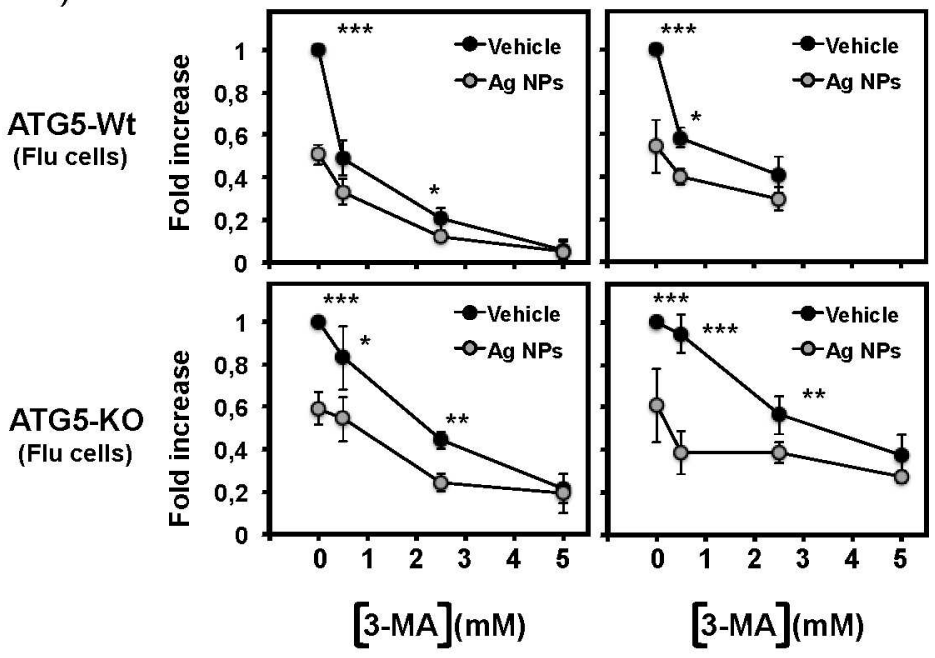

B)
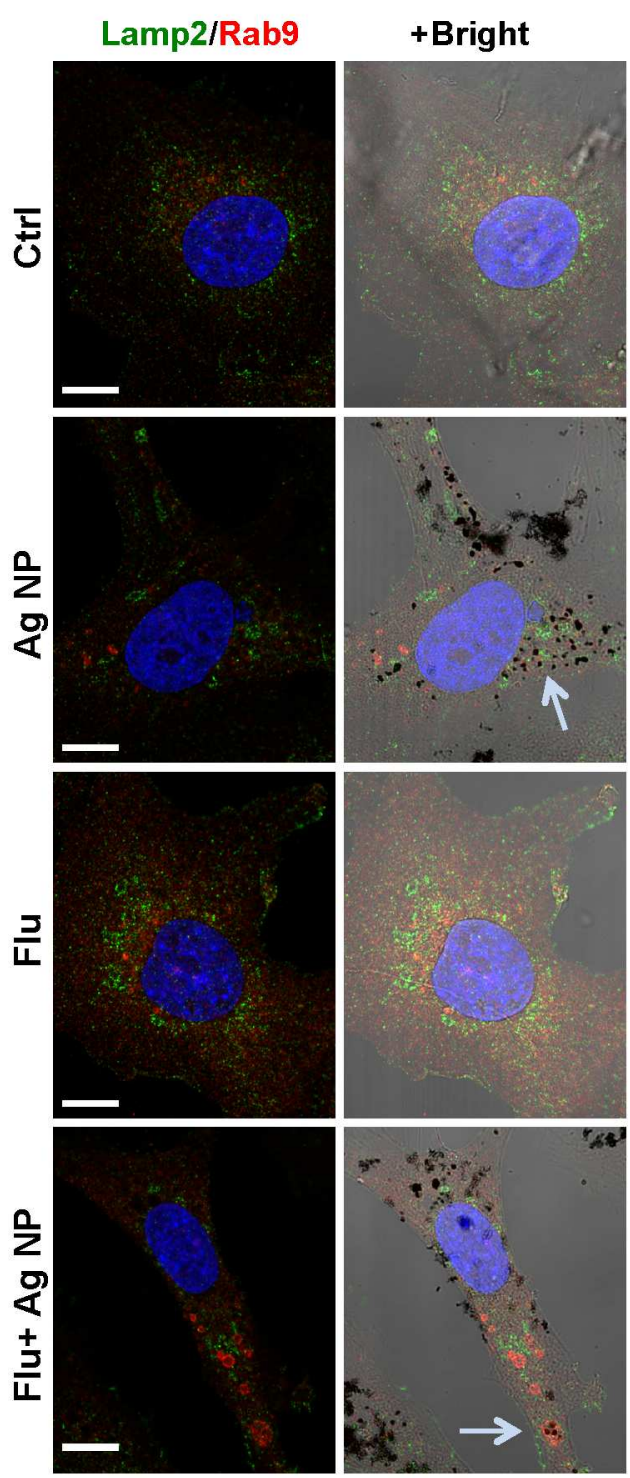

Fig-8 